\title{
DEVELOPMENT OF A CALIBRATION SOURCE FOR MEASUREMENT OF GASEOUS OXIDIZED MERCURY IN AMBIENT AIR
}

\author{
by \\ Matthew Davis \\ Bachelor of Science, Ryerson University 2017
}

\begin{abstract}
A thesis presented to Ryerson University
in partial fulfillment of the

requirements for the degree of

Master of Science

in the program of

Molecular Science
\end{abstract}

Toronto, Ontario, Canada, 2019

() Matthew Davis, 2019 


\section{Author's Declaration}

I hereby declare that I am the sole author of this thesis. This is a true copy of the thesis, including any required final revisions, as accepted by my examiners.

I authorize Ryerson University to lend this thesis to other institutions or individuals for the purpose of scholarly research

I further authorize Ryerson University to reproduce this thesis by photocopying or by other means, in total or in part, at the request of other institutions or individuals for the purpose of scholarly research.

I understand that my thesis may be made electronically available to the public. 


\title{
DEVELOPMENT OF A CALIBRATION SOURCE FOR MEASUREMENT OF GASEOUS OXIDIZED MERCURY IN AMBIENT AIR
}

\author{
Matthew Davis \\ Ryerson University \\ MSc, Molecular Science, 2019
}

\section{Abstract}

A HgCl 2 containing diffusion source was evaluated for its potential usefulness as a calibration source for gaseous oxidized mercury (GOM) measurements. Unlike previous calibration sources described in the literature, this source made use of a flow rate of at least $1 \mathrm{~L} \mathrm{~min}-1$, and was maintained at a temperature of as low as $15^{\circ} \mathrm{C}$. Under these conditions, the source was found to emit GOM at an environmentally relevant level of $0.0905 \mathrm{pg} \mathrm{s}^{-1}$, with a GOM fraction of approximately $78 \%$. The source was found to have a consistent response to temperature, a steady state emission level of $\mathrm{Hg}$ could be rapidly established, and the source was temporally stable. Duplicate sources were compared with one another and found to emit similar levels of $\mathrm{Hg}$ under identical sampling conditions. Various methods of cleaning $\mathrm{HgCl}_{2}$ contaminated items were tested, with the most successful method using a stannous chloride wash solution. 


\section{Acknowledgements}

I would like to thank my research supervisor, Dr. Julia Lu for her support and guidance throughout the completion of this project. I also would like to thank the members of my supervisory committee, Dr. Daniel Foucher, and Dr. Darrick Heyd for their feedback, suggestions, and guidance. I would like to acknowledge fellow MSc student Nicole Rodriguez for her friendly support, Chris von Keyserling for his electrical advice, as well as my friends Morla, Aesha, and Tehreem for their friendship and other assistance during difficult periods in this work. I would like to thank the graduate program administrator, Sarah Kovacs for her patience and guidance during my time enrolled in this program. Finally, I would like to thank my parents and family for their steadfast support. 


\section{Table of Contents}

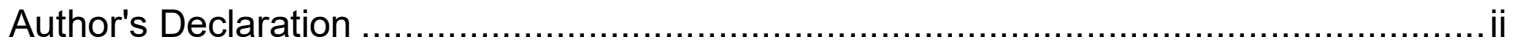

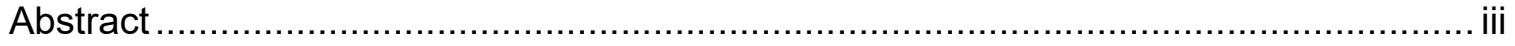

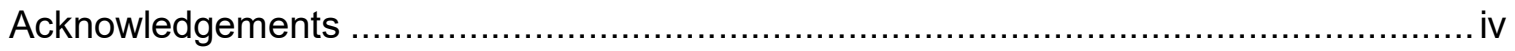

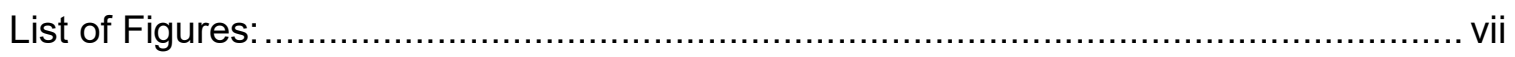

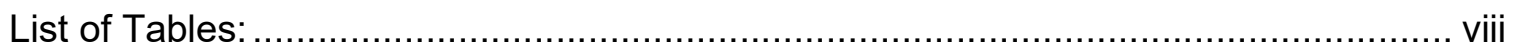

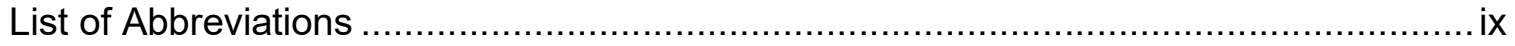

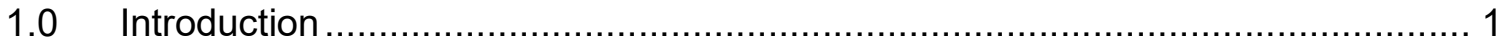

1.1 Physical and Chemical Properties of Mercury and its Compounds ................. 1

1.2 Mercury in the Environment ................................................................. 3

1.2.1 Species distribution, sources, transference and transformation in the Environment and Risks to Human Health ...................................................... 4

1.3 Analytical Techniques for the Measurement of Atmospheric Mercury .............. 7

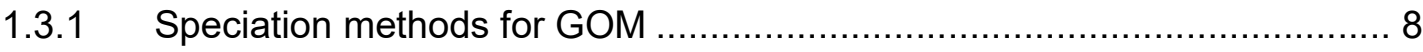

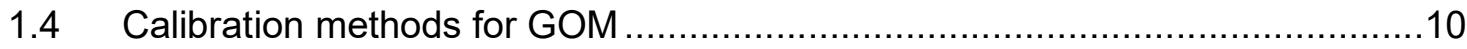

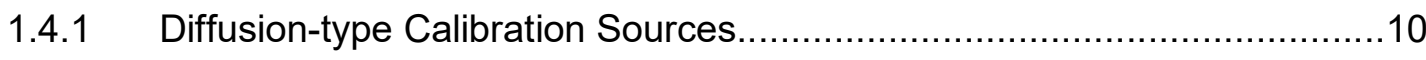

1.4.2 Permeation-type Calibration Sources ................................................14

1.4.3 Summary of Previous Work on GOM Calibration sources …...................17

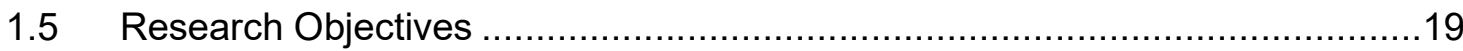

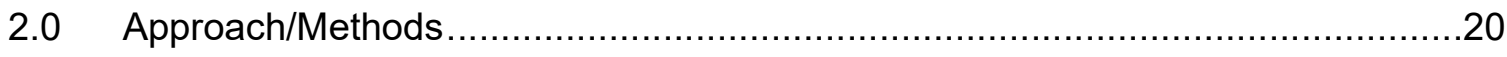

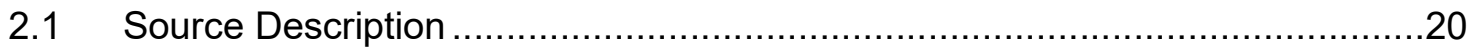

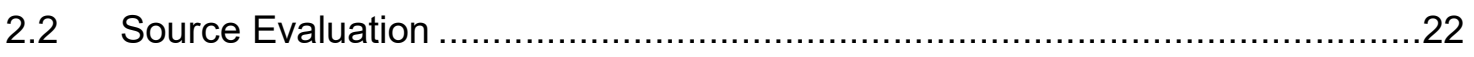

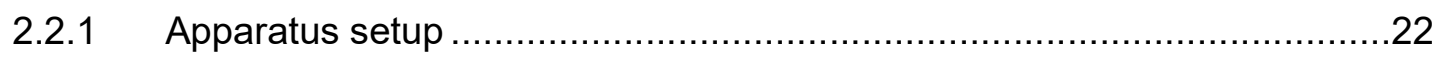

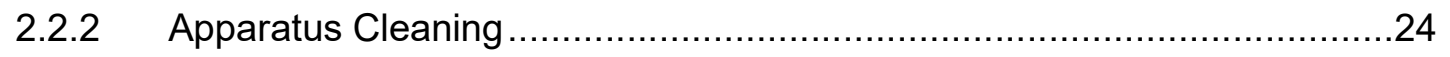

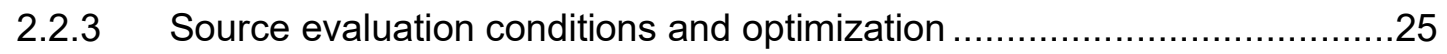

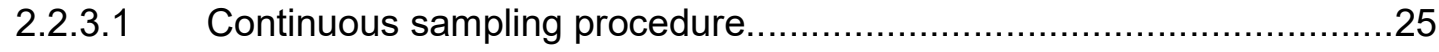

2.2.3.2 Manual sampling procedure

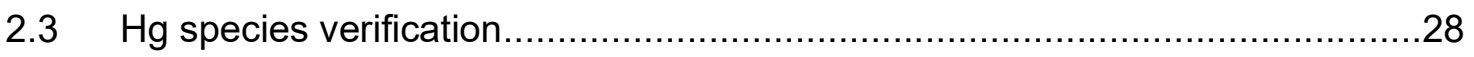

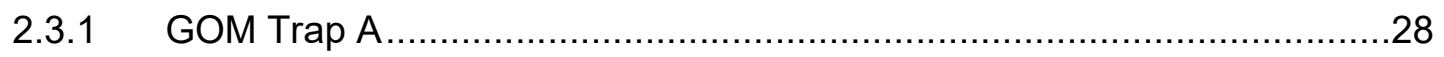

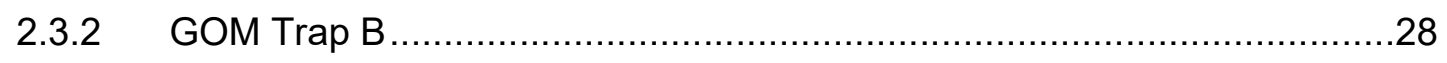

2.3.3 Verification of mercury species of the GOM source .............................28

2.4 Data Analysis, Quality Assurance and Control...............................................

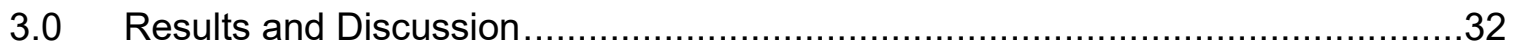

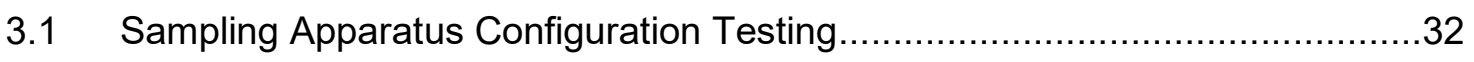

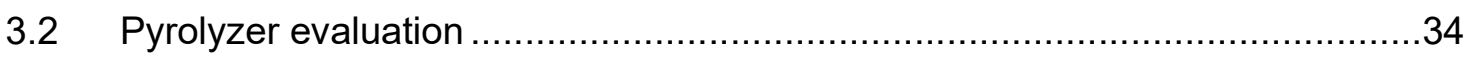




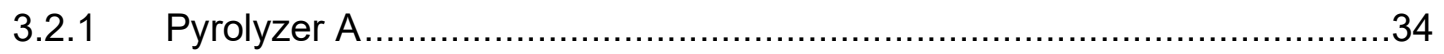

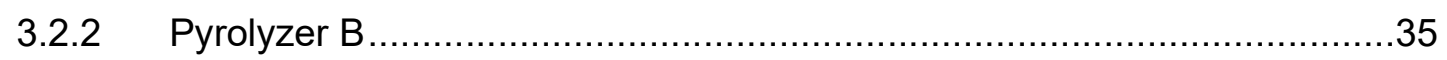

3.3 Modifications to the source to improve stability by increasing line temperature and decreasing source temperature fluctuation ................................................. 38

3.4 Mathematical Modelling of the GOM Source Emission rate ..........................47

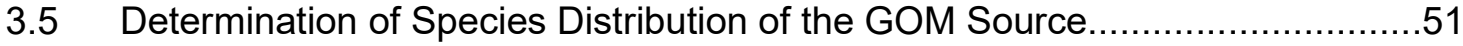

3.6 Impact of 2019 Source Contamination on GOM Source Measurements ..........53

3.6.1 Determination of the effect of GOM source temperature on source

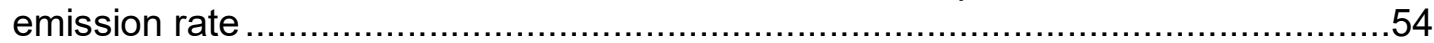

3.6.2 Determination of the species distribution of the GOM source ..................57

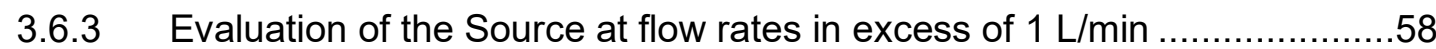

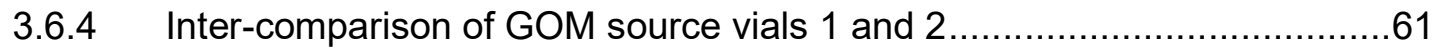

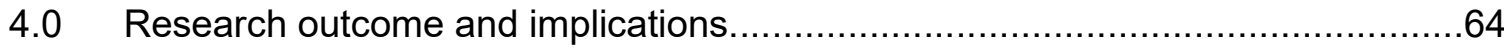

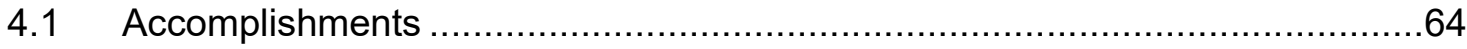

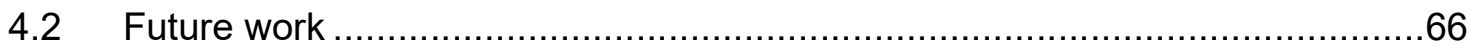

4.2.1 Determining the Reproducibility of Replicate GOM Source Vials ..............66

4.2.2 Extended Testing of Increased Source Flow Rates ...............................67

References .68 


\section{List of Figures:}

Figure 1: Gaseous oxidized mercury source vial and flask ...................................21

Figure 2: Experimental Apparatus used to evaluate the GOM source stability ..............23

Figure 3: "Turn" (A) and "Straight" $(B)$ prospective sampling line configurations ............32

Figure 4: Comparison between measured emission rates at a flow rate of $2.69 \mathrm{~L} \mathrm{~min}^{-1}$ and source temperature of $7.5^{\circ} \mathrm{C}$, before and after increasing the heated pyrolyzer area.

Figure 5: Comparison between measured emission rates at a source flow rate of 4.72 $\mathrm{L} / \mathrm{min}$ and $4.25 \mathrm{~L} / \mathrm{min}$, and a source temperature of $7.5^{\circ} \mathrm{C}$

Figure 6: Scatterplots of measured emission rate arranged by time of sample $(A)$ and sample number $(B)$, at a flow rate of $4.2 \mathrm{~L} / \mathrm{min}$ and a source temperature of $7.5^{\circ} \mathrm{C}$..... 39

Figure 7: Scatterplots of measured emission rate arranged by outside air temperature (A) and sample number $(B)$ at a flow rate of $4.54 \mathrm{~L} / \mathrm{min}$ and source temperature of $7.5^{\circ} \mathrm{C}$

Figure 8: Time series of $\mathrm{Hg}$ measured by the Tekran 2537 Analyzer between 20 November -11 December 2018 at a flow rate of $5 \mathrm{~L} / \mathrm{min}$ and source temperature of $5^{\circ} \mathrm{C}$ while degassing previously adsorbed $\mathrm{Hg}$

Figure 9: Time Series of $\mathrm{Hg}$ emitted from the GOM source, at a temperature of $5^{\circ} \mathrm{C}$ and a flow rate of $5 \mathrm{~L} / \mathrm{min}$.

Figure 10: Dose-Response curves for the GOM source at a flow rate of $1 \mathrm{~L} / \mathrm{min}$, and source temperature set point ranging between $-15^{\circ} \mathrm{C}$ to $5^{\circ} \mathrm{C}$. .54

Figure 11: Dependence of the source $\mathrm{Hg}$ emission rate on source temperature. .56 Figure 12: Time Series of GOM source measurements at a flow rate of $5 \mathrm{~L} / \mathrm{min}$ and a source temperature setting of $-15^{\circ} \mathrm{C}$ on three consecutive days .59

Figure 13: Measured source temperature at flow rates between $1-7 \mathrm{~L} / \mathrm{min}$, and liquid bath set points between $-15-9^{\circ} \mathrm{C}$. 60

Figure 14: Dose response curves for GOM vial 1 and GOM vial 2 at a flow rate of 1 $\mathrm{L} / \mathrm{min}$, and a source temperature setting of $-15^{\circ} \mathrm{C}$ for GOM Vial 1, and a source temperature setting of $-13--12^{\circ} \mathrm{C}$ for GOM Vial 2 


\section{List of Tables:}

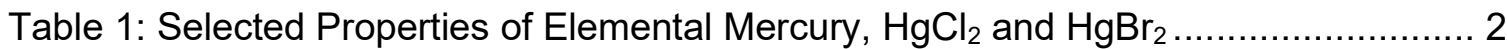

Table 2: Source conditions and GOM emission rate and source concentration of selected $\mathrm{HgCl}_{2}$ diffusion sources

Table 3: Source conditions and GOM emission rate and source concentration of selected GOM permeation sources. 16

Table 4: Summary of the used pyrolyzer characteristics

Table 5: Tabulated data collected for the competing sampling apparatus configurations

Table 6: Measured $\mathrm{Hg}$ concentrations at a source temperature of $5^{\circ} \mathrm{C}$ and source flow rate of $5 \mathrm{~L} / \mathrm{min}$ and Ambient air temperatures.

Table 7: Average measured $\mathrm{Hg}$ concentration from the GOM source at a source temperature set point of $5^{\circ} \mathrm{C}$ and a flow rate of $5 \mathrm{~L} / \mathrm{min}$, before and after the GOM source was moved to an insulated container

Table 8: Daily average emission rate measured from the GOM source following operating condition optimization.

Table 9: Source emission rates measured at each flow rate and temperature combination during the sampling campaign .53

Table 10: Source conditions and Hg species of the GOM source .56

Table 11: Summary of the GOM source emission rate over the temperature range of -15 $-5{ }^{\circ} \mathrm{C}$

Table 12: GOM fraction of the GOM source vapour calculated by difference, with a correction factor applied for the estimated level of trapped GEM

Table 13: Comparison of the measured $\mathrm{Hg}$ emission rates from vials 1 and 2 to the predicted emission rates from the calibration curve. 


\section{List of Abbreviations}

AAS-Atomic absorbance spectroscopy

AFS-Atomic fluorescence spectroscopy

AMNet-Atmospheric Mercury Network

CVAFS—Cold vapour atomic fluorescence spectroscopy

DOHGS-Detector for oxidized Hg species

ECCC_Environment and Climate Change Canada

EPA-Environmental protection agency

EDTA—Ethylenediaminetetraacetic acid

FEP_Fluoroethylene propylene

GEM-Gaseous elemental mercury

GOM-Gaseous oxidized mercury

I.D._-Inner Diameter

O.D.-Outer Diameter

PBM-Particulate-bound mercury

PTFE-Polytetrafluoroethylene

RTI-Research Triangle Institute

TGM-Total gaseous mercury

Tris-Tris(hydroxymethyl)aminomethane 


\subsection{Introduction}

\subsection{Physical and Chemical Properties of Mercury and its Compounds}

Mercury is a silvery transition metal—notably the only metal element that is liquid at room temperature. Its atomic number is 80 , and it has an atomic weight of 200.592. Mercury readily amalgamates with the noble metals, and prior to industrialization, was used in gold and silver mining. ${ }^{1}$ Over the $20^{\text {th }}$ century, mercury production increased from 3600 tons per year in 1900 to as much as 10,000 tons in the early 1970 's, to meet the demand for industrial processes such as chlor-alkali plants, consumer goods such as batteries or dental amalgams, but by the end of the century, due to concerns over mercury's toxic properties, production had dropped to only 2035 tons per year. ${ }^{2}$ Mercury is volatile, with a vapour pressure of $1.22 \times 10^{-3} \mathrm{mmHg}$ at $20^{\circ} \mathrm{C} .^{2}$ It has three oxidation states, the elemental form $\left(\mathrm{Hg}^{0}\right)$, the monovalent form (mercurous mercury, $\mathrm{Hg}^{+}$) which is not stable under environmental conditions, and the divalent form (mercuric mercury, $\mathrm{Hg}^{2+}$ ). The major divalent mercury species in the atmosphere are thought to be mercury halides, especially $\mathrm{HgCl}_{2}$ and $\mathrm{HgBr}_{2}$, but other candidate species exist. Mercury halide salts are white solids at room temperature, that, like elemental mercury, are volatile at room temperature. Selected properties of elemental mercury, $\mathrm{HgCl}_{2}$ and $\mathrm{HgBr}_{2}$ are listed in Table 1. $\mathrm{HgCl}_{2}$ is more volatile than $\mathrm{Hg}^{0}$, with a vapour pressure of $1.3 \mathrm{~mm} \mathrm{Hg}$ at $21^{\circ} \mathrm{C}$. The divalent mercury salts are also significantly more soluble in water than $\mathrm{Hg}^{0}$. In the atmosphere, mercury is largely present as $\mathrm{Hg}^{0}$, which has a longer 
residence time than the oxidized species, which are more prone to deposition than $\mathrm{Hg}^{0}$ due to their higher solubility.

Table 1: Selected Properties of Elemental Mercury, $\mathrm{HgCl}_{2}$ and $\mathrm{HgBr}_{2}$

\begin{tabular}{|l|l|l|l|l|l|}
\hline Compound & $\begin{array}{l}\text { Melting } \\
\text { Point }\left({ }^{\circ} \mathrm{C}\right)\end{array}$ & $\begin{array}{l}\text { Boiling } \\
\text { Point } \\
\left({ }^{\circ} \mathrm{C}\right)\end{array}$ & $\begin{array}{l}\text { Vapour } \\
\text { Pressure } \\
\left(\mathrm{mm} \mathrm{Hg} /{ }^{\circ} \mathrm{C}\right)\end{array}$ & $\begin{array}{l}\text { Density } \\
(\mathrm{g} / \mathrm{mL})\end{array}$ & $\begin{array}{l}\text { Solubility in } \\
\text { Water }\end{array}$ \\
\hline $\mathrm{Hg}^{0}$ & -39 & 357 & $0.0012 / 20^{\circ} \mathrm{C}$ & 13.6 & $\begin{array}{l}3.03 \times 10^{-7} \\
\mathrm{~mol} / \mathrm{kg} @ 25^{\circ} \mathrm{C}\end{array}$ \\
\hline $\mathrm{HgCl}_{2}$ & 277 & 302 & $1.3 / 21^{\circ} \mathrm{C}$ & 5.40 & $\begin{array}{l}0.269 \mathrm{~mol} / \mathrm{kg} \\
@ 25^{\circ} \mathrm{C}\end{array}$ \\
\hline $\mathrm{HgBr}_{2}$ & 237 & 322 & $1 / 136.5^{\circ} \mathrm{C}$ & 6.03 & $\begin{array}{l}0.017 \mathrm{~mol} / \mathrm{kg} \\
@ 25^{\circ} \mathrm{C}\end{array}$ \\
\hline
\end{tabular}




\subsection{Mercury in the Environment}

Mercury occurs naturally in the Earth's crust, principally as cinnabar $(\mathrm{HgS})^{1}$, which is the major source from which mercury is mined. Additionally, mercury is ubiquitously present in low concentrations throughout the Earth's crust, with estimates ranging between $1-10 \mathrm{ppb}$ to as high as $1.1 \mathrm{ppm}$ on average. However, mercury contaminated soils can contain 100's to 10,000's of ppm of mercury. ${ }^{2}$ Currently, the largest use of mercury is in artisanal gold mining in developing countries, which is responsible for $37.1 \%$ of anthropogenic mercury emissions, with other major sources including coal combustion (24.2\%), nonferrous metals production (15.5\%), and cement production (8.8\%). ${ }^{2}$ Anthropogenic emissions make up approximately $30 \%$ of global mercury emissions, with approximately $60 \%$ of global mercury emissions being due to the re-emissions of mercury in environmental reservoirs, and 'new' natural sources (such as volcanic eruptions) making up less than $10 \%$ of emissions. ${ }^{4}$ The increased levels of mercury emissions since the industrial revolution have resulted in the average global mercury deposition levels tripling since $1850 .^{2}$ Mercury is considered to be a 'global pollutant', which is spread from (largely stationary) point sources to pristine natural waters and soils by atmospheric transport. Consequently, an understanding of the behavior of mercury in the atmosphere is enormously important for the study of mercury in the environment. 


\subsubsection{Species distribution, sources, transference and transformation in the}

\section{Environment and Risks to Human Health}

Atmospheric mercury is operationally partitioned into three categories: gaseous elemental mercury (GEM), which consists of $\mathrm{Hg}^{0}$; gaseous oxidized mercury (GOM), which is defined as mercury that can be reduced by stannous chloride in aqueous solutions; and particulate-bound mercury (PBM), which consists of mercury bound to particulate matter. ${ }^{5,6}$ The composition of GOM is unknown, but candidate species include $\mathrm{HgCl}_{2}$, which has been identified in flue gas, and $\mathrm{HgBr}_{2}$, which is implicated in mercury depletion events in the Arctic. ${ }^{7}$

GEM is the major mercury species in the atmosphere, estimated to make up $90 \%$ of atmospheric mercury ${ }^{8}$, has a lengthy residence time, on the order of $0.5-2$ years $^{6}$, and is relatively inert. Due to this lengthy residence time, GEM is responsible for the 'global character' of environmental mercury. GOM is estimated to make up $8 \%$ of atmospheric mercury ${ }^{8}$ (except in point emission sources and arctic GEM depletion events, where the GOM fraction is significantly higher). GOM is quite reactive, and due to being significantly more soluble than GEM (on the order of $10,000 x)^{9}$, is a major factor for atmospheric mercury deposition, with a residence time of only days or weeks ${ }^{6}$. The major source of GOM to the atmosphere is from flue gas but can also be generated in situ from atmospheric reactions with GEM. PBM is estimated to make-up $2 \%$ of atmospheric mercury ${ }^{8}$, and is assumed to consist of GOM that is partitioned between a gaseous-phase and a particulate-bound phase. Although atmospheric mercury mostly consists of GEM, the ratio of species in anthropogenic emissions 
are estimated to be in the range of $50-60: 30-40: 3-10$ for GEM, GOM, and PBM respectively. ${ }^{10}$ This disparity between the emitted species, and those measured in the environment is indicative of the velocity at which GOM is removed from the atmosphere.

While atmospheric mercury almost entirely consists of GEM, in natural waters, the ratio of $\mathrm{Hg}(\mathrm{II})$ is much higher. In the ocean, inorganic mercury is roughly evenly divided between $\mathrm{Hg}(0)$ and $\mathrm{Hg}(\mathrm{II})$, while in fresh water sources, $\mathrm{Hg}(\mathrm{II})$ is the dominant inorganic mercury species. Mercury levels in pristine natural waters vary widely, ranging from below $1 \mathrm{ng} \mathrm{L}^{-1}$, to as much as $90 \mathrm{ng} \mathrm{L}^{-1}$. ${ }^{2}$ Consequently, direct health risks to humans as a result of mercury exposure is most commonly related to exposure from the aquatic environment.

In addition to inorganic $\mathrm{Hg}(0)$ and $\mathrm{Hg}(\mathrm{II})$, mercury in aquatic environments is also present as the organic mono-methyl mercury species. Bacteria-mediated methylation reactions in sediment are responsible for the transformation of inorganic mercury to its organic form, and while methyl mercury in sediment is rapidly reconverted to inorganic mercury, once in the water column, little to no reconversion takes place. ${ }^{2}$ Unlike the inorganic forms of mercury that have low bioavailability, methyl mercury is readily absorbed by the tissues of living organisms. Consequently, methyl mercury bioaccumulates and biomagnifies through an ecosystem, resulting in apex predators and people being exposed to potentially harmful levels of mercury. ${ }^{11}$ Generally, pregnant women are most atrisk for mercury exposure, as the fetus preferentially accumulates methyl mercury, and the developing brain is particularly sensitive to mercury damage. ${ }^{12}$ 
Mercury is a neurotoxin, that in high doses can cause neural degeneration, Minamata disease, or death. ${ }^{13}$ Due to its rapid deposition rate, and as a precursor for methyl mercury, GOM is disproportionately important, relative to its fraction of atmospheric mercury. 


\subsection{Analytical Techniques for the Measurement of Atmospheric}

\section{Mercury}

Atmospheric mercury presents several challenges for the analytical chemist. The principle difficulty is that atmospheric mercury species are present at ultra-trace levels ( $\mathrm{ng} \mathrm{m}^{-3}$ range). It was not until 1975 that a method was developed by T. Hadeishi, D. A. Church, R. D. McLaughlin, B. D. Zak, M. Nakamura, and B. Chang to continuously measure mercury levels in ambient air, using a Zeeman-effect atomic absorption spectrometer. The method detection limit for this technique was $0.2 \mu \mathrm{g} \mathrm{m}^{-3}$, one fifth of the (then current) US EPA guideline ${ }^{14}$ As concerns over mercury in the environment have grown, more sensitive instruments have been developed, with detection limits as low as 0.10 $\mathrm{ng} \mathrm{m}^{-3}$ being typical. Methods have also been developed for the analysis of PBM, in which PBM is removed from an air stream using filters or impactors, and the PBM is found by difference with total gaseous mercury (TGM). Other methods trap PBM, digest it, and then analyze the mercury species directly. The main instrument used for atmospheric mercury monitoring in North America is the family of Tekran 2537 analyzers developed by Tekran corporation. The first version of this instrument was introduced in 1992 and has a detection limit of less than $0.1 \mathrm{ng} \mathrm{m}^{-3}$. A speciation system using $\mathrm{KCl}$-coated denuders to capture $\mathrm{GOM}$ (commercially available as the Tekran 1130), and a quartz filter to capture PBM (commercially available as the Tekran 1135) was also developed. ${ }^{5}$ 


\subsubsection{Speciation methods for GOM}

Traditional methods for the speciation of GOM species make use of the higher solubility of GOM to selectively capture it from the atmosphere, followed by the use of wet chemistry to convert the mercury species to elemental mercury, and quantify it by atomic absorbance spectroscopy (AAS) or atomic fluorescence spectroscopy (AFS). The US Environmental Protection agency (EPA) developed a standard method, EPA Method 29, for the speciation of coal flue gas, which makes use of two impingers containing $10 \% \mathrm{H}_{2} \mathrm{O}_{2}$ in $5 \% \mathrm{HNO}_{3}$ solution, followed by two impingers of $4 \% \mathrm{KMnO}_{4}$ in $10 \% \mathrm{H}_{2} \mathrm{SO}_{4}$ solution, with the effect that $\mathrm{Hg}^{2+}$ species are captured in the peroxide solutions, while the $\mathrm{Hg}^{0}$ species are captured in the permanganate solutions. ${ }^{15}$ Modifications of EPA Method 29 include the Ontario Hydro method, in which one of the peroxide solutions is replaced by three impingers containing $1 \mathrm{~N} \mathrm{KCl}$ in deionized water, the Tris-buffer method, in which the peroxide impingers are replaced by two impingers containing $1 \mathrm{M}$ tris(hydroxymethyl)aminomethane (tris) dissolved in deionized water, using ethylenediaminetetraaceteic acid (EDTA) as a chelating agent, and the Research Triangle Institute (RTI) method, which replaces one of the peroxide solutions with deionized water. ${ }^{16}$

For GOM in ambient air, more sensitive methods were needed. $\mathrm{An} \mathrm{HCl}$ mist chamber method was developed by Stratton et $\mathrm{al}^{17}$ to capture GOM species in ambient air. The mist chamber makes use of a nebulizer to generate a mist of $\mathrm{HCl}$, which solubilizes and traps GOM in ambient air as it is drawn through the mist chamber. After the sampling period, the acid solution is treated with $\mathrm{SnCl}_{2}$ to 
reduce the GOM to $\mathrm{Hg}^{0}$, which is then detected using cold vapour atomic fluorescence spectroscopy (CVAFS). The method detection limit for the mist chamber method is $6-10 \mathrm{pg} \mathrm{m}^{-3}$. A significant downside to the mist chamber method, and the methods based on EPA Method 29 is that the analyst must carry out wet chemistry to analyze the samples, and do not allow for continuous sample analysis. Automated speciation methods are more convenient for the analyst.

The most successful automated method for speciating GOM developed during the 1990's and early 2000's made use of KCl-coated denuders. GOM species have a high affinity for the $\mathrm{KCl}$ coating, and selectively adsorb onto its surface. In early methods, the $\mathrm{KCl}$-coated denuders were used to capture GOM from the atmosphere, and then chemically extracted, resulting in high analytical blanks. ${ }^{5} \mathrm{~A}$ refinement of this method makes use of thermal desorption at $450^{\circ} \mathrm{C}$ to release the GOM species from the $\mathrm{KCl}$-coated denuder, which is then converted to GEM using a quartz pyrolyzer at $900^{\circ} \mathrm{C}$, and detected using CVAFS.${ }^{18} \mathrm{~A}$ further refinement of this method redesigned the denuder where, rather than a single tubular denuder, an annular denuder constructed of two coaxial tubes with airflow directed through the annular space is used, which increased the collection efficiency per unit area by 30 , and the maximum flowrate through the denuder from $1 \mathrm{~L} \mathrm{~min}{ }^{-1}$ to $10 \mathrm{~L} \mathrm{~min}^{-1} .{ }^{19}$ This method was developed by Landis et al, and commercialized by Tekran. ${ }^{5}$ The method was convenient, however recent studies have demonstrated that the capture efficiency of the $\mathrm{KCl}$ denuders is heavily dependant on humidity and ozone levels, dropping to as little 
as $20-54 \%$ in poor conditions, and currently no commercially available calibration method exists. ${ }^{20-25}$ Another method that has been used is the Detector for Oxidized Hg Species (DOHGS) designed by the University of WashingtonBothell, which uses two Tekran 2537 analyzers to separately determine TGM and GEM, determining GOM by difference. This system uses a quartz pyrolyzer packed with quartz wool, heated to $650^{\circ} \mathrm{C}$ to measure $\mathrm{THg}$, and a quartz wool packed trap to exclude GOM from the airstream measured by the other instrument to determine GEM. ${ }^{26}$

\subsection{Calibration methods for GOM}

Calibration sources for elemental mercury are commercially available, however, direct, reliable calibration sources for GOM have been more difficult to develop. Largely, these difficulties are related to the properties of GOM candidate species, especially their 'stickiness', where GOM species have a tendency to adhere to any available surface. Consequently, most analytical instruments intended for the analysis of GEM are unable to directly measure GOM, requiring its conversion to GEM first. Typical methods involve either chemical reduction with $\mathrm{SnCl}_{2}$ or thermal reduction using $600-800^{\circ} \mathrm{C}$ pyrolysis. Calibration methods that have been evaluated for GOM in ambient air include diffusion-type sources, and permeation tube-type sources.

\subsubsection{Diffusion-type Calibration Sources}

During the 1990's, the most common type of calibration source was the diffusion-type source, the characteristics of several of these are listed in Table 2. The first oxidized mercury source for calibration was a diffusion-type device 
described by Larjava in $1993^{27}$, for the purpose of calibrating a flue gas analyzer, consisting of a few grams of $\mathrm{HgCl}_{2}$ contained within a small glass vial contained within a sealed diffusion cell, maintained at a temperature of $90^{\circ} \mathrm{C}$ with an oil bath. Nitrogen gas was pumped into the bottom of the diffusion cell, and exited through the top, carrying with it $\mathrm{HgCl}_{2}$ vapour. To ensure that the GOM did not adhere to the sampling line, the line was heated to prevent mercury vapour condensation. A later study making use of this device reported a mercury vapour concentration (at a flowrate of $300 \mathrm{~mL} / \mathrm{min}$ ) between $100-165 \mu \mathrm{g} \mathrm{m}^{-3} .{ }^{28}$ While this is a reasonable concentration for calibrating a flue gas analyzer, the resulting concentration is too high to be used for ambient mercury analyzers. The released species were reported to be approximately $80 \%$ GOM and $20 \%$ GEM. ${ }^{28}$

Table 2: Source conditions and GOM emission rate and source concentration of selected $\mathrm{HgCl}_{2}$ diffusion sources

\begin{tabular}{|l|l|l|l|l|l|}
\hline Study & $\begin{array}{l}\text { Source } \\
\text { Temperature } \\
\left({ }^{\circ} \mathrm{C}\right)\end{array}$ & $\begin{array}{l}\text { Source } \\
\text { Flow } \\
\text { Rate }(\mathrm{mL} \\
\left.\mathrm{min}^{-1}\right)\end{array}$ & $\begin{array}{l}\text { Emission } \\
\text { rate }(\mathrm{pg} \\
\left.\mathrm{min}^{-1}\right)\end{array}$ & $\begin{array}{l}\text { Concentration } \\
\left(\mathrm{ng} \mathrm{m}^{-3}\right)\end{array}$ & $\begin{array}{l}\text { GOM } \\
\text { Fraction } \\
(\%)\end{array}$ \\
\hline $\begin{array}{l}\text { Wang et } \\
\text { al. }^{28}\end{array}$ & 90 & 300 & 333,000 & $\begin{array}{l}100-165 \mu \mathrm{g} \\
\mathrm{m}^{-3}\end{array}$ & 80 \\
\cline { 1 - 5 } $\begin{array}{l}\text { Xiao et } \\
\text { al. }{ }^{18}\end{array}$ & $20-24.5$ & $<1000$ & $\begin{array}{l}\text { Not } \\
\text { reported }\end{array}$ & $544.4 \pm 40.8$ & 80 \\
\hline \multirow{2}{*}{$\begin{array}{l}\text { Feng et } \\
\text { al. }\end{array}$} & 11.80 & 500 & $14.2+/-2.0$ & $28.4 \pm 4.0$ & $97.1 \pm 1.84$ \\
\cline { 2 - 5 } & 5.00 & 500 & $5.6+/-0.5$ & $11.2 \pm 1.0$ & \\
\cline { 2 - 5 } & 0.00 & 500 & $2.4+/-0.4$ & $4.8 \pm 0.8$ & \\
\hline
\end{tabular}


The source conditions were modified by Xiao et al for application to the tubular denuder method for capturing GOM from the atmosphere. The source was maintained between $20-21^{\circ} \mathrm{C}$, and released mercury vapour with an average concentration of $544.4 \pm 40.8 \mathrm{ng} \mathrm{m}^{-3} .{ }^{18}$ The source continued to be prone to emitting $\mathrm{Hg}^{0}$ in addition to $\mathrm{HgCl}_{2}$, with another study determining that about $20 \%$ of the total mercury emitted was GEM rather than GOM. During that study, the source emitted mercury vapour with concentrations between $230-400 \mathrm{ng} \mathrm{m}^{-}$ ${ }^{3}$ and $1340-1580 \mathrm{ng} \mathrm{m}^{-3}$ (the source dimensions were modified, resulting in the different ranges of concentration). Conclusions that can be drawn from these results are that the source is quite variable, with significant relative deviation (7.5$26 \%$ ), and that the concentrations are significantly higher than those present in the ambient environment. This work also demonstrated the strong temperature dependence of the GOM source, with the source concentration decreasing by 2 3 orders of magnitude, as the source temperature decreased from $90^{\circ} \mathrm{C}$ to $20^{\circ} \mathrm{C} .{ }^{30}$ Further work was necessary to both improve the stability of the source, and to have it generate levels of mercury relevant to the environment.

Significant work on the diffusion-type source was carried out by Feng et al, using a diffusion-type source constructed to the specifications described in the previous work by Wang et al. A modification was made to the source conditions, rather than maintaining the source at or above room temperature, the source was maintained below room temperature, at a range between $-5-11.80^{\circ} \mathrm{C}$. This was advantageous for two reasons, one being that by maintaining the source below room temperature, the GOM vapour was less prone to condensation on the 
sampling line, making it unnecessary to heat the sampling line, and that due to the observed temperature-dependence of the GOM source concentration, a lower source temperature might result in a more environmentally relevant airstream concentration. ${ }^{29}$ The flow rate through the source was $500 \mathrm{~mL} \mathrm{~N} \mathrm{~min}^{-1}$, but it was then diluted with $9.5 \mathrm{~L} \mathrm{~N}_{2} \mathrm{~min}^{-1}$ to match the $10 \mathrm{~L} \mathrm{~min}^{-1}$ flow rate of the newly commercialized Tekran 1130 GOM speciation system that the source was being used to evaluate. The mercury emission rate of this source under several temperature conditions is shown in Table 2. The emitted species were reported to be approximately $97 \%$ GOM. ${ }^{29}$ Evidently, a GOM source emitting mercury vapour with a concentration of $27.2-3.6 \mathrm{ng} \mathrm{m}^{-3}$ (diluted to $1.36-0.18 \mathrm{ng} \mathrm{m}^{-3}$ ) is more applicable to mercury levels in the environment, which have an ambient level on the order of $1-2 \mathrm{ng} \mathrm{m}^{-3}$, though the level of GOM specifically would be much lower, on the order of $80-160 \mathrm{pg} \mathrm{m}^{-3}$. Following this result however, little work was conducted on the diffusion-type GOM calibration sources, with further research making use of permeation-type GOM sources. 


\subsubsection{Permeation-type Calibration Sources}

The use of permeation tubes for trace-gas standards was described in $1966,{ }^{31}$ and has since been commercialized. The principle of operation is as follows: A small quantity of the desired analyte (which is usually a volatile liquid, though in the case of GOM species, solid divalent mercury species, e.g. $\mathrm{HgCl}_{2}$, or $\mathrm{HgBr}_{2}$, are used) is enclosed in a permeable tube (examples have been constructed of materials such as fluoroethylene propylene (FEP), or thin-wall polytetrafluorethylene (PTFE)), and immersed in the flow of an inert gas. The volatilized analyte slowly permeates through the tubing walls at a constant rate, which varies according to the physical characteristics of the system, e.g. temperature, permeable area of the tubing, permeability of the gas through the tubing, etc. Permeation tubes for some GOM species are commercially available but are more commonly custom-made by researchers. The selected characteristics of several permeation-tube based calibration sources are listed in Table 3. 
Table 3: Source conditions and GOM emission rate and source concentration of selected GOM permeation sources

\begin{tabular}{|c|c|c|c|c|c|}
\hline Study & $\begin{array}{l}\text { Source } \\
\text { Temperature } \\
\left({ }^{\circ} \mathrm{C}\right)\end{array}$ & $\begin{array}{l}\text { Flow } \\
\text { Rate (mL } \\
\left.\mathrm{min}^{-1}\right)\end{array}$ & $\begin{array}{l}\text { Emission } \\
\text { rate }(p g \\
\left.\min ^{-1}\right)\end{array}$ & $\begin{array}{l}\text { Source } \\
\text { Concentration } \\
\left(\mathrm{ng} \mathrm{m}^{-3}\right)\end{array}$ & $\begin{array}{l}\text { GOM } \\
\text { Fraction (\%) }\end{array}$ \\
\hline $\begin{array}{l}\text { Stratton et } \\
\text { al. }{ }^{17}\end{array}$ & 50 & * & * & $\begin{array}{l}0.50-3.0 \\
\text { (diluted) }\end{array}$ & * \\
\hline $\begin{array}{l}\text { Landis et } \\
\text { al. }^{5}\end{array}$ & 50 & * & * & $\begin{array}{l}0.40-4.0 \\
\text { (diluted) }\end{array}$ & 100 \\
\hline $\begin{array}{l}\text { McClure et } \\
\text { al. }{ }^{32}\end{array}$ & 30 & 93.1 & $22.1 / 17.7$ & $237.4 / 190.1$ & $92.8 \pm 16.3$ \\
\hline \multirow[t]{2}{*}{$\begin{array}{l}\text { Lyman et } \\
\text { al. }^{22}\end{array}$} & \multirow[t]{2}{*}{100} & \multirow[t]{2}{*}{100} & $\begin{array}{l}900 \\
\left(\mathrm{HgCl}_{2}\right)\end{array}$ & 9000 & 72 \\
\hline & & & $\begin{array}{l}600 \\
\left(\mathrm{HgBr}_{2}\right)\end{array}$ & 6000 & 72 \\
\hline
\end{tabular}

${ }^{*}$ Not reported

A permeation-type GOM source was used by Stratton et al, to evaluate the capture efficiency of the mist-chamber GOM capture method. The source made use of $\mathrm{HgCl}_{2}$ and was maintained at a temperature of $50^{\circ} \mathrm{C}$. By purging the source with an inert gas, and diluting with laboratory air, GOM concentrations in the range of $500-3000 \mathrm{pg} \mathrm{m}^{-3}$ were generated. While not as excessively high as the early diffusion-type GOM sources, it was significantly higher than the 50 $100 \mathrm{pg} \mathrm{m}^{-3}$ levels of GOM that Stratton et al had measured using the mist chamber method from the ambient environment. ${ }^{17} \mathrm{~A}$ permeation tube GOM source was also used in the development of the annular denuder method, which 
was commercialized in the Tekran 1030 automated GOM analyzer. ${ }^{5}$ With the problem of measuring GOM in the atmosphere apparently solved, interest in GOM sources diminished. However, later studies demonstrated that $\mathrm{KCl}$-coated denuders, which had become widely used for analyzing atmospheric GOM, were less effective at capturing GOM in environmental conditions than they were in laboratory conditions, ${ }^{24}$ which increased interest once more in GOM sources that could be used to calibrate measurements under environmental conditions.

McClure et al made use of an $\mathrm{HgBr}_{2}$ permeation tube based GOM source to calibrate measurements from an Atmospheric Mercury Network (AMNet) site. The source was maintained at $30^{\circ} \mathrm{C}$ and made use of a flow rate of $93.1 \pm 1.7 \mathrm{scc}$ $\min ^{-1}$, with a resulting emission rate of $17.7 \pm 0.8 \mathrm{pg} \mathrm{min}^{-1}$. When dilution gas was introduced (to satisfy the flowrate requirements of the Tekran 1130 analyzer), the resulting concentration of $\mathrm{Hg}$ was $863 \mathrm{pg} \mathrm{m}^{-3}$. Using this source, McClure et al found an average $\%$ recovery using $\mathrm{KCl}$ denuders in ambient air at only $31.8 \pm 12.0 \%$, losing $2 / 3$ 's of the GOM recovery in laboratory air. The source released GOM at an excessively high rate, with the concentration of GOM in the airflow from the permeation source being $190 \mathrm{ng} \mathrm{m}^{-3}$, requiring a 200x dilution to reach the level of $863 \mathrm{pg} \mathrm{m}^{-3}$ which might be comparable to that found in the ambient air. ${ }^{32}$ Further work was carried out by Lyman et al, who designed an automated calibration system using $\mathrm{HgBr}_{2}$ and $\mathrm{HgCl}_{2}$ permeation-type $\mathrm{GOM}$ sources. The permeation tubes were maintained at $100^{\circ} \mathrm{C}$, with a flowrate of 100 $\mathrm{mL} \mathrm{min}{ }^{-1}$. The observed GOM emission rates ranged from $15 \mathrm{pg} \mathrm{s}^{-1}$ to $6 \mathrm{pg} \mathrm{s}^{-1}$ for the $\mathrm{HgCl}_{2}$ source, and $10 \mathrm{pg} \mathrm{s}^{-1}$ to $6 \mathrm{pg} \mathrm{s}^{-1}$ for the $\mathrm{HgBr}_{2}$ source. While this 
concentration is quite high (as much as $9000 \mathrm{ng} \mathrm{m}^{-3}$ ), the calibration system only injected for $7-100 \mathrm{~s}$ in hour-long sampling periods, resulting in a much lower observed concentration. However, due to the design of the calibration unit, no comparison could be made between ambient air $\mathrm{KCl}$-denuder recovery, and laboratory air $\mathrm{KCl}$-denuder recovery. ${ }^{22}$

\subsubsection{Summary of Previous Work on GOM Calibration sources}

Generally, GOM calibration sources in the literature have demonstrated a reasonable degree of stability and have been useful for the development and evaluation of GOM speciation methods. However, certain deficiencies continue to exist:

- High source temperature resulting in high concentrations: to minimize sample loss, recent examples ${ }^{22,32}$ maintain their sampling apparatuses well above room temperature, a consequence of this is that the GOM source's resulting emission rate becomes excessively high, with GOM source airstream concentrations ranging from $\sim 200 \mathrm{ng} \mathrm{m}^{-3}, 32$ to as high as $9000 \mathrm{ng} \mathrm{m}^{-3} \cdot 22$

- Low source flow rates resulting in high uncertainty: Due to the high GOM source airstream concentrations, researchers find it necessary to use low flow rates through their GOM sources (as low as $100 \mathrm{~mL} \mathrm{~min}^{-1}$, though older sources also used flow rates of up to $500 \mathrm{~mL} \mathrm{~min}^{-1}$ ), which by itself introduces some degree of uncertainty due to the low volume.

- Use of a dilution gas leading to sample loss and increased uncertainty: Generally, the instruments that are used with these calibration systems 
are designed to be used with a flow rate higher than $100-500 \mathrm{~mL} \mathrm{~min}{ }^{-1}$, with speciation systems such as the Tekran 1130 requiring a flow rate of $10 \mathrm{~L} \mathrm{~min}^{-1}$, and the commonly used Tekran 2537 analyzer that is frequently used requiring a flow rate of $1 \mathrm{~L} \mathrm{~min}^{-1}$. These dilution systems introduce an additional layer of complexity, and in some cases have been shown to possibly result in sample loss. ${ }^{25}$ 


\subsection{Research Objectives}

The objective of this research is to develop a GOM source, which emits GOM vapour at an environmentally relevant level. To the best of our knowledge, the developed source is unique in the literature for, rather than using a low flow rate $\left(100-500 \mathrm{~mL} \mathrm{~min}{ }^{-1}\right)$ which is then diluted, utilizing a flow rate of at least 1 $\mathrm{L} / \mathrm{min}$, with a maximum flow rate of up to $10 \mathrm{~L} \mathrm{~min}^{-1}$. As well, rather than maintaining the GOM source and sample pathway at temperatures above room temperature to minimize deposition, the GOM source is maintained below room temperature $\left(-15-10^{\circ} \mathrm{C}\right)$, to both minimize deposition and minimize the emission rate of GOM from the source. Once the stability of the source is established under laboratory conditions, the $\mathrm{Hg}$ species released from the GOM source will be evaluated using a GOM trap to determine the species fractionation. 


\subsection{Approach/Methods}

\subsection{Source Description}

The GOM source device used is shown in Figure 1. It consists of a small glass vial containing solid $\mathrm{HgCl}_{2}$, fitted with a capillary neck. The vial is enclosed within a custom-made glass bubbler, with the bubbler stem cut at an appropriate height to fit over the capillary neck. Airflow is supplied to the GOM source bottle via 1/8" O.D. PTFE tubing, through the side of the bubbler's stopper. Air then exits the GOM source by flowing through the stem. GOM vapour within the source vial diffuses into the airstream and is carried out of the GOM source. A liquid bath is used to maintain the temperature of the GOM source below room temperature (temperatures between $-15-10^{\circ} \mathrm{C}$ were used). 


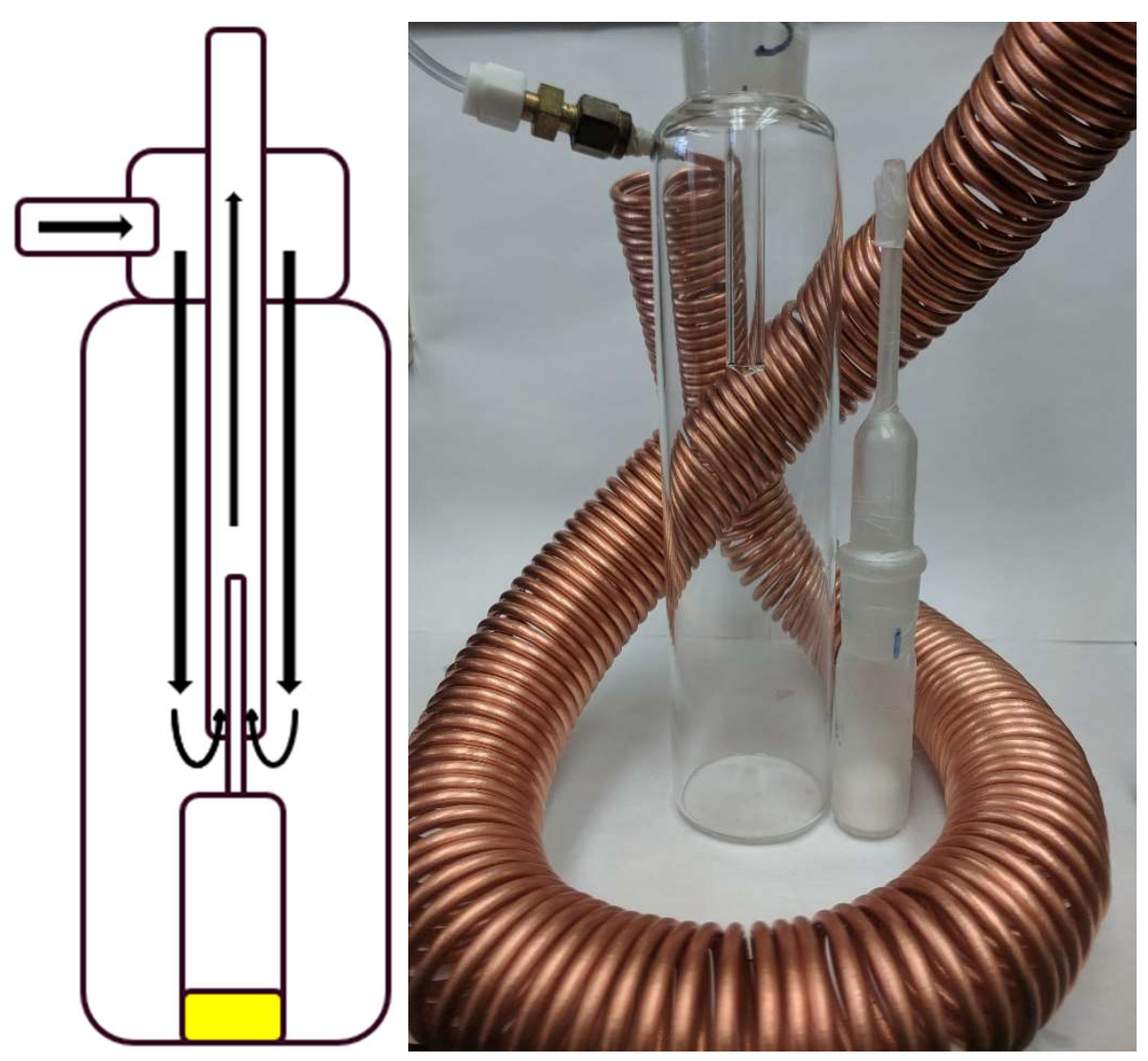

Figure 1: Gaseous oxidized mercury source vial and flask 


\subsection{Source Evaluation}

\subsubsection{Apparatus setup}

The apparatus used for the evaluation of the GOM source is shown in

Figure 2. Three separate air lines are present, each supplied with zero (mercury free) air from the zero-air source (consisting of a laboratory compressed air source, an oil trap, a moisture trap, and an activated carbon mercury trap). The lines include a zero-air line for the Tekran 2537A zero-air inlet, used for calibrations, a background line used to establish the baseline level of mercury in the system, and a GOM source line, through which mercury vapour from the GOM source can either be measured by the Tekran analyzer, or vented, as the source must run continuously to maintain a steady state equilibrium. Prior to the Tekran inlet is a pyrolyzer, which is used to thermally reduce GOM to GEM, for measurement in the Tekran analyzer. Additionally, a soda-lime guard column is used to prevent un-reduced GOM from entering the Tekran analyzer to prevent damage to the instrument. The arrangement of the valves as depicted in Figure 2 is the configuration suitable for measuring the background level of $\mathrm{Hg}$ within the system. Two pyrolyzers were used during this work. 


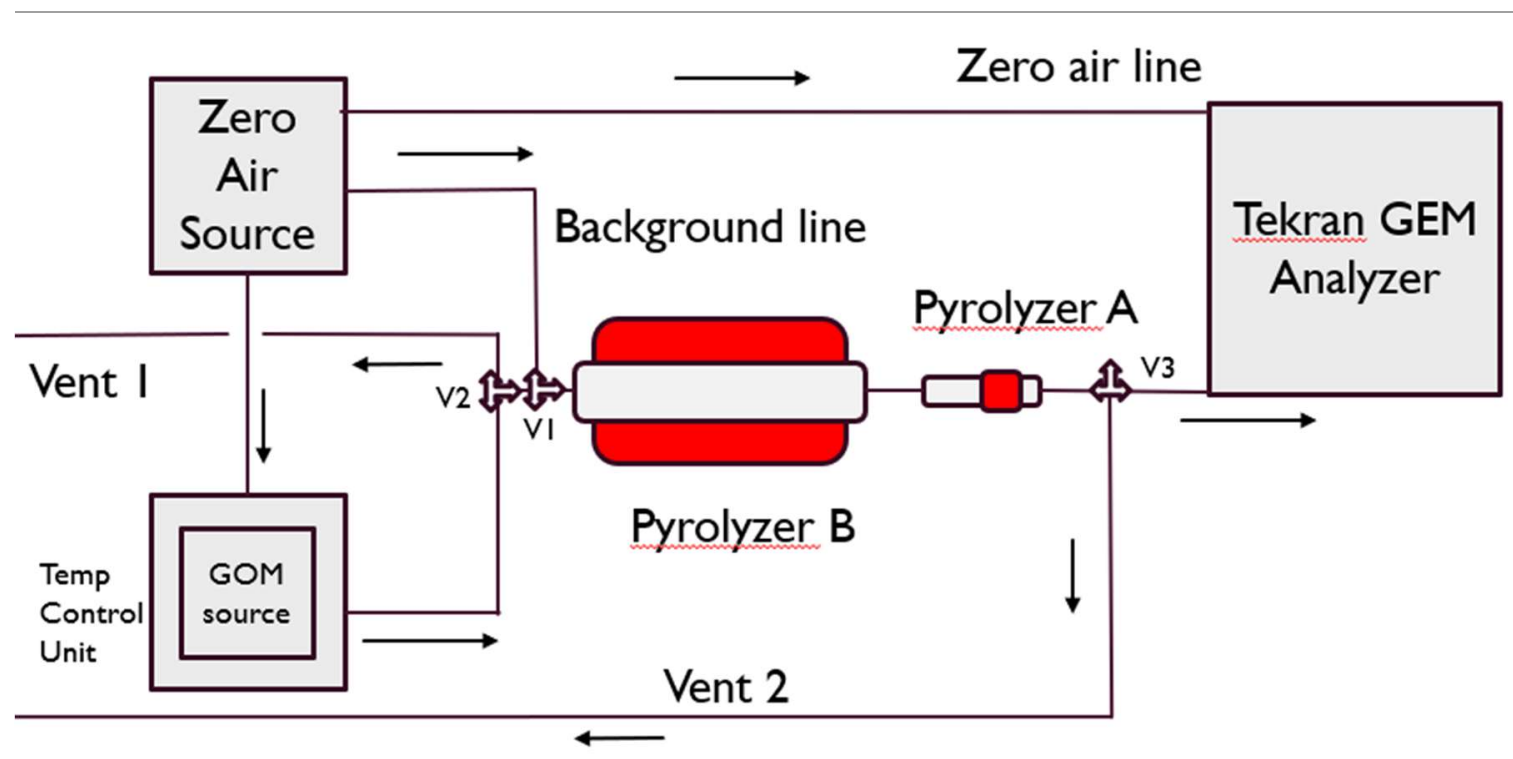

Figure 2: Experimental Apparatus used to evaluate the GOM source stability

\subsubsection{Pyrolyzer $A$}

This pyrolyzer consists of a custom-made quartz tube, approximately 20 $\mathrm{cm}$ in length, $1.2 \mathrm{~cm}$ in diameter, tapering to $0.625 \mathrm{~cm}$ O.D. at either end. The heated length is $5 \mathrm{~cm}$, and contains packed quartz wool. The pyrolyzer is heated using a nichrome wire coil ( $5 \mathrm{~cm}$ length, $1 \mathrm{~cm}$ diameter), powered using a $10 \mathrm{~A}$ Tenma variac autotransformer. At $20 \mathrm{~V}$, the measured temperature within the pyrolyzer (without airflow) was determined to be $750^{\circ} \mathrm{C}$.

\subsubsection{Pyrolyzer $B$}

As with pyrolyzer A, the type-B pyrolyzer is constructed of a quartz tube, with the following dimensions: approximately $50 \mathrm{~cm}$ in total length, with the main cylinder having a length of $40 \mathrm{~cm}$, diameter of $2.5 \mathrm{~cm}$, and each end tapering to 1 $\mathrm{cm}$ diameter, $5 \mathrm{~cm}$ length. The interior diameter of the tube ends is $0.8 \mathrm{~cm}$, and the pyrolyzer is of uniform thickness (i.e. $0.1 \mathrm{~cm}$ thick walls). Within the tube, at the midpoint, is a length of $3.5 \mathrm{~cm}$ packed quartz chips, around which the tube 
narrows slightly, fixing the quartz chips in place. The two pyrolyzers are compared in Table 4. The pyrolyzer is heated using a Lindberg/Blue M tube furnace, of suitable interior diameter to fit the pyrolyzer, set to $800^{\circ} \mathrm{C}$. To avoid heat from the pyrolyzer from melting the Teflon tubing that was attached to the pyrolyzer, a fan is used to cool the furnace outlet.

Table 4: Summary of the used pyrolyzer characteristics

\begin{tabular}{|l|l|l|l|l|}
\hline Pyrolyzer & Dimensions (cm) & $\begin{array}{l}\text { Heater length } \\
(\mathrm{cm})\end{array}$ & $\begin{array}{l}\text { Operating } \\
\text { temperature } \\
\left({ }^{\circ} \mathrm{C}\right)\end{array}$ & $\begin{array}{l}\text { Packing } \\
\text { material }\end{array}$ \\
\hline A & $\begin{array}{l}20 \times 1.2 \text { O.D (body) } \\
0.625 \\
\text { O.D.(inlet/outlet) }\end{array}$ & 5 & $650-750$ & Quartz wool \\
\hline B & $\begin{array}{l}40 \times 2.5 \mathrm{~cm} \text { O.D. } \\
\text { (body) } \\
5 \times 1 \text { O.D. (0.8 I.D.) } \\
\text { (inlet/outlet) } \\
\text { Total length: } 50\end{array}$ & $\begin{array}{l}\text { Approximately } \\
\text { Tota }\end{array}$ & 800 & $\begin{array}{l}\text { Quartz } \\
\text { Chips }\end{array}$ \\
\hline
\end{tabular}

\subsubsection{Apparatus Cleaning}

One of the most important considerations in the analysis of trace levels of mercury is ensuring that the sampling apparatus is as free of mercury as possible. A 1:10 $\mathrm{HNO}_{3}$ solution was used to remove excess mercury from the sampling line. Further background reduction was achieved by heating the sampling line to induce desorption of mercury. Leak-checking the apparatus and applying PTFE tape to each fitting prevented any leaks. Consequently, a background level of less than $0.10 \mathrm{ng} \mathrm{m}^{-3} \mathrm{GEM}$ (the detection limit of the Tekran 2537 analyzer) was achieved. 


\subsubsection{Apparatus Decontamination}

After nearly 12 months of continuous operation without issue, the sampling apparatus became highly contaminated following a 2-week pause in operations between December 2018 - January 2019. After the cleaning procedure from 2.2.2 was found to be ineffective (due to the high levels of $\mathrm{Hg}$ present), the contaminated PTFE tubing was discarded and replaced with new tubing. The copper tubing used to cool the source was discarded and replaced with new tubing. The PTFE fittings and T-junctions that could not be replaced were washed repeatedly with $\mathrm{HNO}_{3}$ solutions ranging in concentration from 1:10 - 1:3

-1:1. High temperature $\mathrm{Hg}$-free air was also used to purge the various components. The resulting background level in the system was reduced to approximately $0.5 \mathrm{ng} \mathrm{m}^{-3}$ with the pyrolyzer inactive, and approximately $2-5.5$ $\mathrm{ng} \mathrm{m}^{-3}$ with the pyrolyzer active.

A subsequent contamination of the vial-containing flasks also occurred, and similar decontamination procedures as listed above were used. However, the most effective decontamination method made use of a stannous chloride wash solution to reduce the $\mathrm{HgCl}_{2}$ adsorbed to the containers to $\mathrm{Hg}^{0}$. Due to the decreased 'stickiness' of GEM, the remaining $\mathrm{Hg}$ was able to be removed via purging the system with $\mathrm{Hg}$-free air. 


\subsubsection{Source evaluation conditions and optimization}

\subsubsection{Continuous sampling procedure}

The general evaluation procedure is as follows:

1) Sample zero air through the sampling line for 100 minutes with the pyrolyzer active.

2) Sampling valve $V 1$ is rotated 90 degrees, such that the GOM from the source was being analyzed.

3) Following the sampling period, sampling valve $V 1$ is returned to its original state, and the sampling line was purged for 30 minutes with the pyrolyzer active, to ensure that no oxidized mercury remained in the sampling line.

Using this method, the GOM source is evaluated with respect to day-today consistency in measurements, and variation within a day's measurements. Weekly, the source flow rate is increased, beginning with a flow rate of $1 \mathrm{~L} / \mathrm{min}$, and proceeding to $10 \mathrm{~L} / \mathrm{min}$ at $1-1.5 \mathrm{~L} \mathrm{~min}^{-1}$ increments. (Due to a lengthy equilibration time of $48-72$ hours, it is not efficient to modify the flow rate more frequently than once per week).

\subsubsection{Manual sampling procedure}

Due to the source concentration measured in 2019 increasing by two orders of magnitude over the values measured during 2018 (described further in 0), the procedure described in 2.2.3.1 is not effective. (As a trace $\mathrm{Hg}$ analyzer, the resulting quantity of $\mathrm{Hg}$ would potentially damage the instrument.) Instead, the procedure was modified as follows: 
1) Mercury free air is measured through the sampling line for 100 minutes as the pyrolyzer increases in temperature to $800^{\circ} \mathrm{C}$.

2) Following this period to record a baseline, the Tekran analyzer was switched to its internal zero air source, valve $\mathrm{V} 1$ is rotated 90 degrees to accept air from the GOM source line, valve V2 is switched to direct air from the GOM source through the pyrolyzer, and valve V3 switched to direct GOM source air through vent line 2.

3) After allowing the situation to stabilize for 15 minutes, a manual sampling procedure was followed:

i. The analyzer's zero air source was disabled.

ii. After 5 seconds, valve V3 was switched to direct air from the GOM source into the analyzer. Following the predetermined sampling time, valve V3.

iii. After 5 seconds, the analyzer's zero air source was reactivated.

iv. A minimum of 6 data points with a minimum of 3 different sampling times were recorded to establish a linear response between sampling time and measured concentration. This method was used to evaluate the GOM source at several temperatures, though unlike in 2.2.3.1, measurements could only be done at a flow rate of 1 L/min. 


\subsection{Hg species verification}

To verify the species released from the GOM source, a GOM trap was used to selectively capture GOM from the airstream. The basic design was a quartz tube packed with quartz chips, coated with $\mathrm{KCl}$. This selectively captures GOM due to: (1) GOM's characteristic stickiness; and (2) the large formation constant for the $\mathrm{Cl}^{-}: \mathrm{Hg}^{2+}$ complex. Two different GOM traps were used, which are described in more detail below.

\subsubsection{GOM Trap A}

The first GOM trap used consists of a quartz tube, $2.3 \mathrm{~cm}$ diameter, one end is a screw-cap reducer to $0.625 \mathrm{~cm}$ diameter tube. The input is a $0.9 \mathrm{~cm}$ diameter tube at a right-angle to the tube. $15 \mathrm{~cm}$ of tubing following the input tubing is filled with quartz chips. $6.5 \mathrm{~cm}$ after the quartz chips is $1.5 \mathrm{~cm}$ of quartz wool. The total length of the quartz tube is approximately $45 \mathrm{~cm}$. A saturated solution of $\mathrm{KCl}$ was used to coat the quartz chips with $\mathrm{KCl}$. This trap was effective at capturing GOM from the air, but it was not convenient to desorb mercury from the trap using a dry method.

\subsubsection{GOM Trap B}

The packed quartz chips within Pyrolyzer B were found to be sufficient to quantitatively collect GOM from the airstream, as a result Pyrolyzer B was simply used as the GOM trap instead.

\subsubsection{Verification of mercury species of the GOM source}

Two separate procedures were used to evaluate the species distribution of the GOM source. The first made use of GOM trap A, and simply measured the quantity of $\mathrm{Hg}$ measured without the trap present and compared it to the quantity 
of $\mathrm{Hg}$ measured with the trap present. The difference between these measurements (i.e. TGM and GEM) would be taken as GOM. The more complex procedure made use of GOM trap B and attempted to additionally recover the collected GOM and establish mass balance between the TGM value, and the GEM and GOM values. The procedure is as follows:

1) The sampling system is arranged with pyrolyzer B (i.e. GOM trap B) upstream of pyrolyzer A. Both pyrolyzers are at room temperature, and the baseline $\mathrm{Hg}$ level within the system is recorded.

2) A spike of air from the GOM source is made to the system. The recorded signal is $\mathrm{Hg}^{0}$. (With three traps, consisting of packed quartz chips, quartz wool, and soda lime between the source and the analyzer, it is unlikely any GOM could be detected in this step)

3) After measuring the baseline for an additional 2 cycles, pyrolyzer B is activated, and heated to $650-750^{\circ} \mathrm{C}$. An $\mathrm{Hg}$ signal from this step is considered as GOM-2, or GOM species that successfully broke through the first trap.

4) After any spike from iii is collected, and the baseline is measured for at least two cycles, the furnace is activated to heat pyrolyzer B to $800^{\circ} \mathrm{C}$. One of the programs used for this was to increase the furnace temperature from room temperature to $350^{\circ} \mathrm{C}$ over 10 minutes, followed by a 5 -minute dwell at $350^{\circ} \mathrm{C}$, followed by a $10-$ minute increase to $800^{\circ} \mathrm{C}$. An $\mathrm{Hg}$ signal from this step is considered 
as GOM-1, or GOM species that were collected on the first GOM trap.

5) Following the return to the baseline, a replicate spike is made to the system from the GOM source. This $\mathrm{Hg}$ signal is considered as the TGM value. 


\subsection{Data Analysis, Quality Assurance and Control}

- Background checking: Prior to measuring air from the GOM source, the background mercury level in the sampling line was recorded for at least 30 minutes to ensure a stable baseline was present.

- Calibration: The Tekran 2537A GEM analyzer was calibrated weekly using standard injections of GEM, using its built-in calibration function.

- Statistical analysis: The first and last data-point of every sampling run was discarded (since they would contain both zero-air and GOM source air.) Data analysis was carried out using $R$ to calculate significance and correlation tests. 


\subsection{Results and Discussion}

\subsection{Sampling Apparatus Configuration Testing}

For ease of use, the original design of the sampling apparatus made use

of the configuration shown in Figure $3 \mathrm{~A}$, in which air from the GOM source is directly vented to the atmosphere; when sampling, the Tekran analyzer's pump

draws $1 \mathrm{~L} / \mathrm{min}$ from the air stream. It was considered that due to the known 'stickiness' of GOM, sample loss could occur due to the $90^{\circ}$ turn, and that a better configuration would be that shown in Figure $3 \mathrm{~B}$, where the sample air stream travels straight to the pyrolyzer, which was expected to minimize sample loss. Both configurations were tested, with the GOM source set at a temperature of $7.5^{\circ} \mathrm{C}$, and a flow rate of $1.02 \mathrm{~L} / \mathrm{min}$.

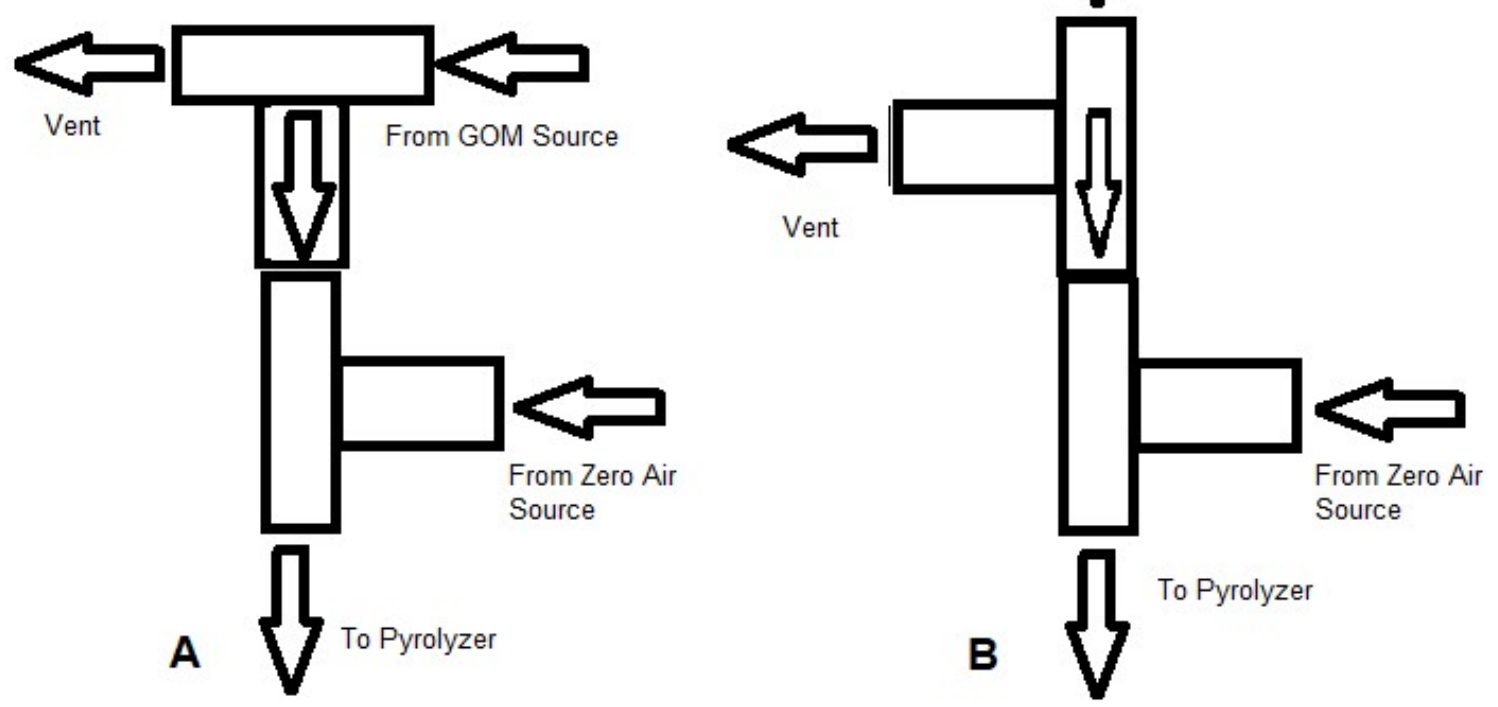

Figure 3: "Turn" (A) and "Straight" (B) prospective sampling line configurations 
The results of the configuration testing are tabulated in Table 5. The data indicates that on 2 of the 3 days where both configurations were tested, a significant difference existed between the two configurations. However, in one case this was due to the 'Turn' configuration having a lower emission rate than the 'Straight' configuration, in the other, the situation was reversed (A Q-test failed to reject the 09-04-18 dataset). Additionally, the tests on 11 April and 12 April are significantly different from one other. Overall, the mean emission rate for both configurations was not significantly different $(p=0.82)$. As there was no significant difference between the two configurations overall, but the coefficient of variation for the "straight" configuration was significantly larger than the "turn" configuration, it was decided to proceed using the "turn" configuration."

Table 5: Tabulated data collected for the competing sampling apparatus configurations

\begin{tabular}{|c|c|c|c|}
\hline Date & $\begin{array}{l}\text { 'Turn' } \\
\text { Configuration } \\
(\bar{x} \pm s)(\mathrm{pg} / \mathrm{s})\end{array}$ & $\begin{array}{l}\text { 'Straight' } \\
\text { Configuration } \\
(\bar{x} \pm s)(\mathrm{pg} / \mathrm{s})\end{array}$ & t-test probability \\
\hline $05-04-18$ & $\begin{array}{l}0.109 \pm 0.0048 \\
(n=16)\end{array}$ & $\begin{array}{l}0.107 \pm 0.0064 \\
(n=17)\end{array}$ & $p=0.274$ \\
\hline $09-04-18$ & $\begin{array}{l}0.114 \pm 0.0046 \\
(n=12)\end{array}$ & $\begin{array}{l}0.146 \pm 0.0098 \\
(n=14)\end{array}$ & $p<0.0001$ \\
\hline $10-04-18$ & $\begin{array}{l}0.113 \pm 0.0082 \\
(n=15)\end{array}$ & $\begin{array}{l}0.107 \pm 0.0096 \\
(\mathrm{n}=26)\end{array}$ & $p=0.044$ \\
\hline $11-04-18$ & 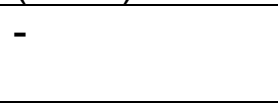 & $\begin{array}{l}0.097 \pm 0.009 \\
(n=14)\end{array}$ & - \\
\hline $12-04-18$ & $\begin{array}{l}0.112 \pm 0.0036 \\
(n=9)\end{array}$ & - & - \\
\hline Total: & $\begin{array}{l}0.112 \pm 0.0060 \\
(n=52)\end{array}$ & $\begin{array}{l}0.112 \pm 0.019 \\
(n=71)\end{array}$ & $p=0.82$ \\
\hline
\end{tabular}




\subsection{Pyrolyzer evaluation}

\subsubsection{Pyrolyzer A}

In March 2018, mercury vapour from the GOM source was analyzed using pyrolyzer $\mathrm{A}$, at a source temperature set-point of $7.5^{\circ} \mathrm{C}$, and a source flow rate of 2.69 L/min. The data from the initial sampling is shown in Figure $4(\mathrm{~A})$. During this period, a strong correlation was visible between the measured emission rate and the sampling time, with a Pearson correlation coefficient of 0.8168 . An explanation that was considered for this phenomenon was that in the original configuration of the apparatus, the heating coil did not cover the entire length of the quartz wool packing material within the pyrolyzer. The result would be that some GOM (which is quite sticky) was trapped upstream of the heated area and would slowly diffuse into the heated area of the pyrolyzer and then be re-emitted.

To solve this, the heating coil was stretched to cover the entire quartz wool area. The data from this configuration is shown in Figure $4(\mathrm{~B})$. The result is that the correlation between emission rate and sampling time is significantly weaker $(R=0.3870)$. A visual inspection suggests that the temporal trend is confined to the first $15-20$ minutes of sampling, after which point no clear temporal trend is visible. 


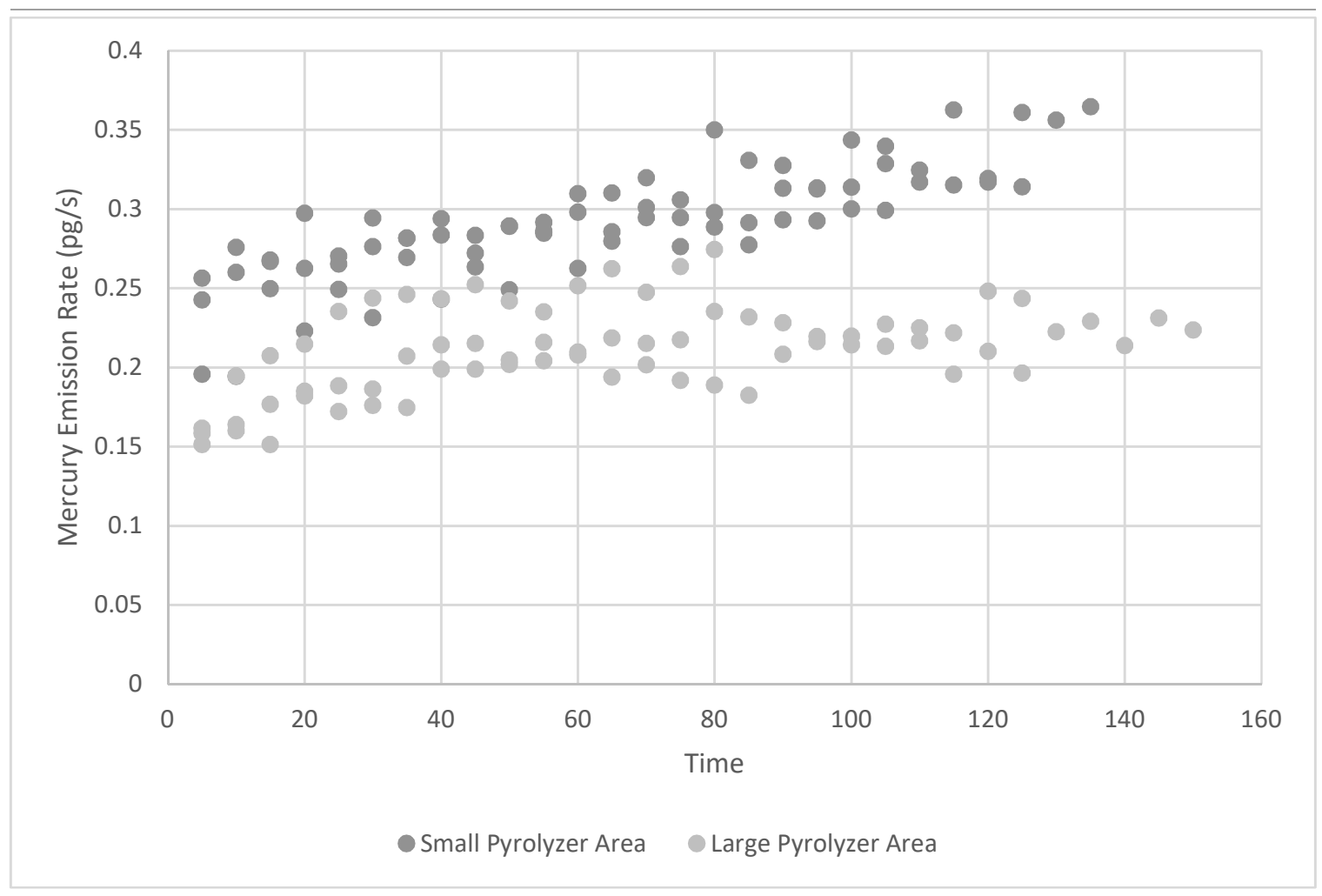

Figure 4: Comparison between measured emission rates at a flow rate of $2.69 \mathrm{~L} \mathrm{~min}^{-1}$ and source temperature of $7.5^{\circ} \mathrm{C}$, before and after increasing the heated pyrolyzer area.

As it had been demonstrated that a limited heating area could potentially present issues, and that pyrolyzer A couldn't be relied upon to quantitatively reduce GOM as it entered the pyrolyzer, it was thought that the situation could be improved further by making use of the larger pyrolyzer B, which had a heated length of approximately $35 \mathrm{~cm}$, and could be maintained at a temperature of up to $800^{\circ} \mathrm{C}$.

\subsubsection{Pyrolyzer B}

Data was collected using pyrolyzer B between March $19^{\text {th }}$ and March $22^{\text {nd }}$, with the source temperature set at $7.5^{\circ} \mathrm{C}$, and a flow rate increased (to decrease source concentration) to $4.25 \mathrm{~L} /$ min while not sampling, but $4.72 \mathrm{~L} /$ min during sampling (March $19^{\text {th }}-20^{\text {th }}$ ) and after a modification to the air line, a flow rate of 
4.25 L/min at all times (March $21^{\text {st }}-22^{\text {nd }}$ ). The original apparatus design was found to be flawed: when sampling was not underway, the flow rate in the source line was $4.25 \mathrm{~L} / \mathrm{min}$, and in the background air line, $\sim 1 \mathrm{~L} / \mathrm{min}$; while sampling was underway, the latter flow rate was reduced to $0 \mathrm{~L} / \mathrm{min}$ (as it was now blocked), and the source flow rate was increased to $4.72 \mathrm{~L} / \mathrm{min}$ (as both lines used the same air source). A strong temporal trend was associated with the measurements made during this first period (Figure 5), and it was considered that this might be caused by this apparatus design dis-equilibrating the source during use. The system was modified to incorporate a venting valve for the background air line so that the flow rate in both lines was kept the same, regardless of which was being measured by the $\mathrm{Hg}$ analyzer. However, as shown in Figure 5, this did not resolve the temporal trend. An observation was made that days on which the outside air temperature was unusually hot or cold appeared to be correlated with days on which the mean emission rate was unusually high or low. Due to this, it was hypothesized that there might be a relationship between the outside (ambient) air temperature and the source emission rate, although the causative mechanism for this was not entirely clear. Consequently, further work was done to investigate this correlation, as described in section 3.3. 


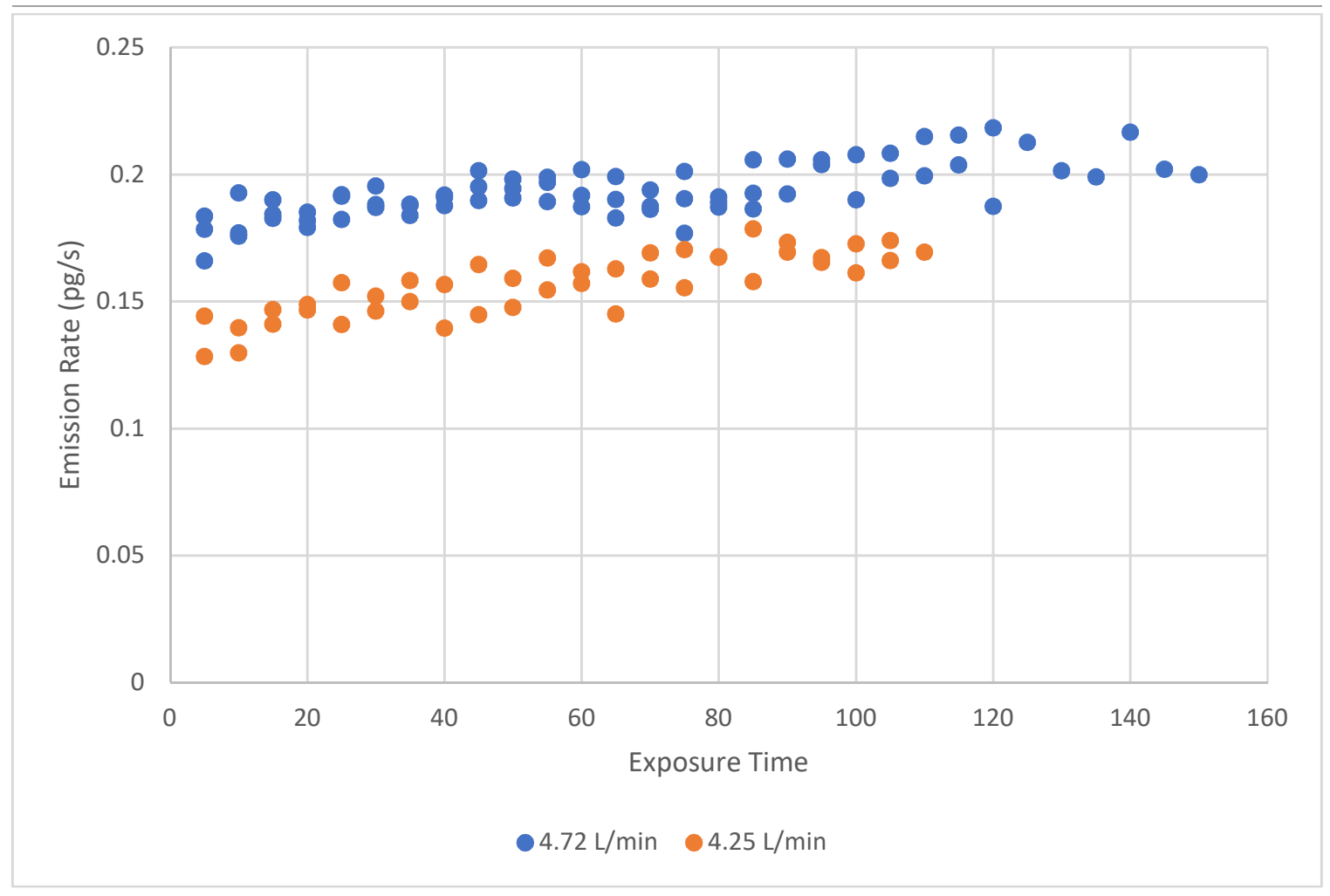

Figure 5: Comparison between measured emission rates at a source flow rate of 4.72 $\mathrm{L} / \mathrm{min}$ and $4.25 \mathrm{~L} / \mathrm{min}$, and a source temperature of $7.5^{\circ} \mathrm{C}$ 
3.3 Modifications to the source to improve stability by increasing line temperature and decreasing source temperature fluctuation

As indicated in Figure 5, a temporal trend is visible in the measured emission rate. An alternative to the "ambient air temperature" hypothesis was that there might be a build-up of mercury in the system, which caused an increase over time. To test this, the sampling procedure was modified to sample GOM source air for $\sim 120$ minutes, followed by sampling zero-air until the baseline was re-established, then sampling the GOM source air once again. If the temporal trend was due to an $\mathrm{Hg}$ build-up, the result would be that the two sampling groups would mirror each other (i.e. both would begin at a low value, then increase over time to higher and higher values). However, as indicated in Figure 6, this was not the case, the data from the second group is a direct continuation of the data from the first group. 


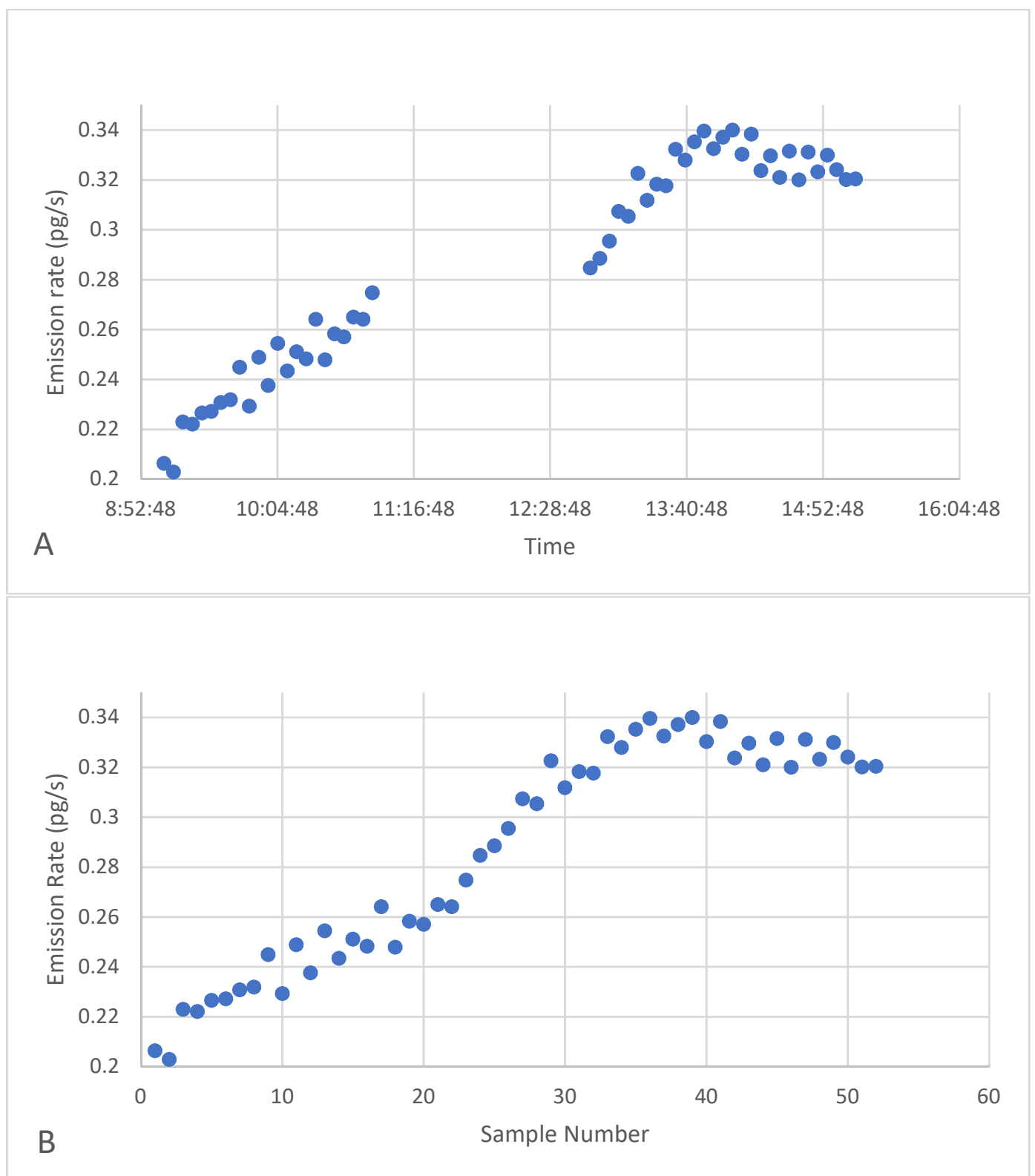

Figure 6: Scatterplots of measured emission rate arranged by time of sample (A) and sample number (B), at a flow rate of $4.2 \mathrm{~L} / \mathrm{min}$ and a source temperature of $7.5^{\circ} \mathrm{C}$

To test the hypothesis that ambient air temperature was responsible for the observed temporal trend, air temperature data from a local weather monitoring station (4340’00.00” N, 79²4'00.000” W) operated by Environment and Climate Change Canada (ECCC) was used. An example of the contrast 
between the generic temporal correlation and the outside air temperature correlation is shown in Figure 7. A lengthy analysis (covered in detail in section 3.4) was unable to establish that this temporal trend had a significant effect on the measured $\mathrm{Hg}$ values over a large sample size, other than increasing the variance in the data. 


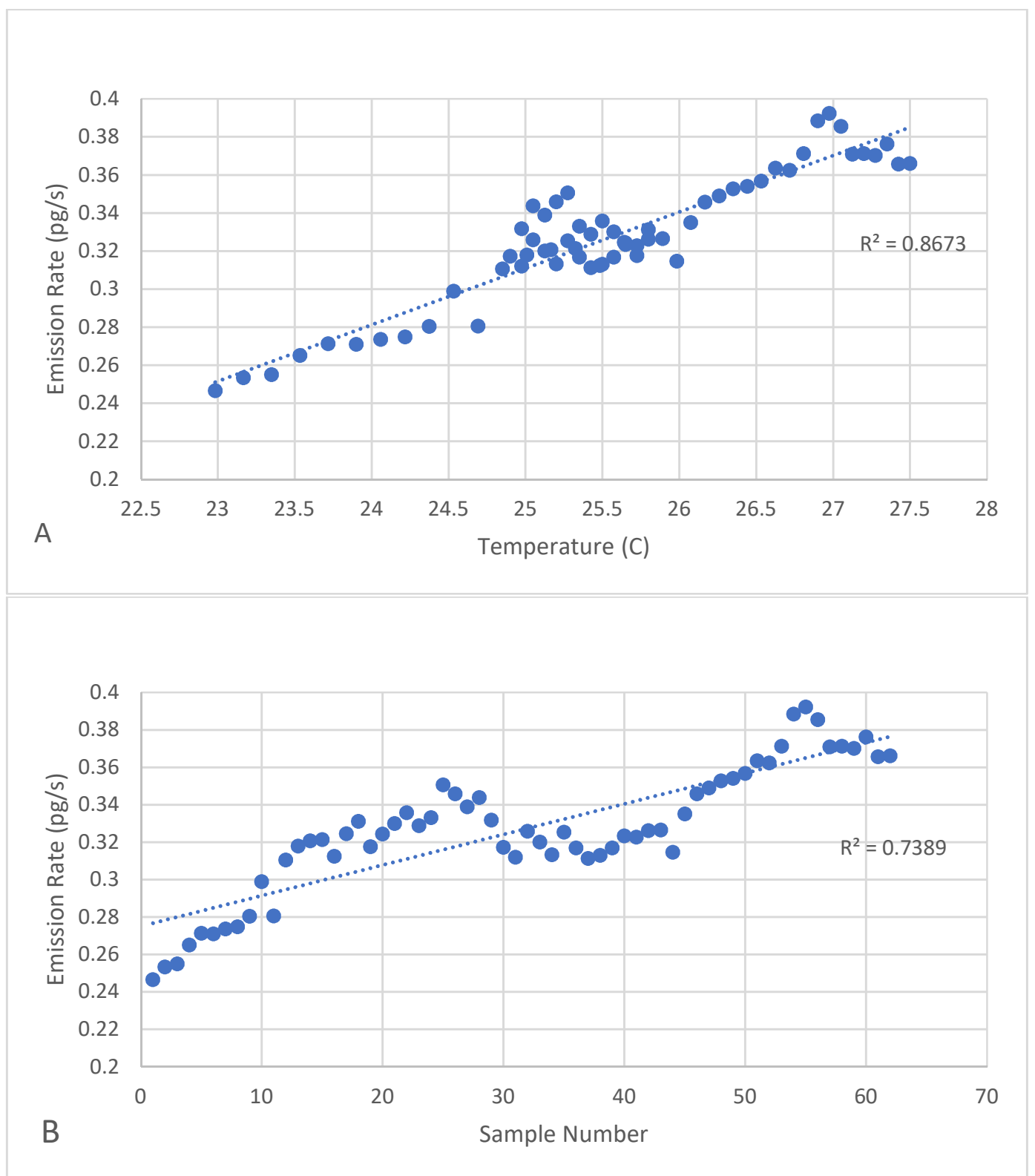

Figure 7: Scatterplots of measured emission rate arranged by outside air temperature (A) and sample number (B) at a flow rate of $4.54 \mathrm{~L} / \mathrm{min}$ and source temperature of $7.5^{\circ} \mathrm{C}$ 
In the fall of 2018, it was observed that periods of cold weather (resulting in decreased temperatures within the lab) corresponded to drops in the measured $\mathrm{Hg}$ concentration, as shown in Table 6. Following the activation of the building's central heating system, the situation stabilized. However, with this evidence that the lab air temperature had a dramatic effect on the measured $\mathrm{Hg}$ concentration, it seemed clear that the earlier observations of an erratic temporal trend could be attributed to instabilities in the lab air temperature of the lab.

Table 6: Measured $\mathrm{Hg}$ concentrations at a source temperature of $5^{\circ} \mathrm{C}$ and source flow rate of $5 \mathrm{~L} / \mathrm{min}$ and Ambient air temperatures.

\begin{tabular}{|l|l|l|}
\hline Date & Air Temperature $\left({ }^{\circ} \mathrm{C}\right)$ & $\begin{array}{l}\mathrm{Hg} \text { Concentration } \pm \mathrm{S} \\
\left(\mathrm{ng} \mathrm{m}^{-3}\right)\end{array}$ \\
\hline $25-09-18$ & 18.7 & $1.02 \pm 0.09$ \\
\hline $27-09-18$ & 14.7 & $0.77 \pm 0.09$ \\
\hline $05-10-18$ & 10.0 & $0.69 \pm 0.08$ \\
\hline $09-10-18$ & 20.2 & $1.52 \pm 0.12$ \\
\hline $10-10-18$ & 21.9 & $1.45 \pm 0.11$ \\
\hline $11-10-18$ & 19.8 & $1.33 \pm 0.09$ \\
\hline $12-10-18$ & $16.9^{*}(9.6)$ & $0.68 \pm 0.15$ \\
\hline $16-10-18$ & $14.3^{*}(8.3)$ & $0.69 \pm 0.16$ \\
\hline $17-10-18$ & $19.9^{*}(7.9)$ & $1.20 \pm 0.10$ \\
\hline $19-10-18$ & $20.0^{*}(11.6)$ & $1.12 \pm 0.12$ \\
\hline $24-10-18$ & $20.0^{*}(5.2)$ & $1.14 \pm 0.12$ \\
\hline
\end{tabular}

* Denotes temperatures measured within the lab, other temperatures obtained from a local ECCC weather monitoring station. 
To address this, the GOM source apparatus (including liquid bath) was relocated into an insulated container. Consequently, while the source continued to be maintained at $5-10^{\circ} \mathrm{C}$ (depending on the source setting), the air line downstream of the source was heated to $30-35^{\circ} \mathrm{C}$ by the waste heat from the GOM source cooler. As a result, the effect of variations in the inside lab temperature on measured source concentration was eliminated.

Following this relocation, the GOM signal from the source was measured on several subsequent days. As shown in Figure 8, the measured $\mathrm{Hg}$ concentration was initially quite high—approximately $4.41 \mathrm{ng} \mathrm{m}^{-3}$ —but it decreased over time, until it reached a low value of $2.42 \mathrm{ng} \mathrm{m}^{-3}$ that was replicated in a subsequent week's measurement of $2.44 \mathrm{ng} \mathrm{m}^{-3}$. This suggests that GOM had been lost through deposition to the downstream air tubing, and that by increasing the temperature of the system, degassing of the GOM had taken place. Additionally, a comparison with an earlier data set under identical flow rate and temperature conditions indicates that in the previous configuration, as much as half of the GOM vapour released from the source was lost through deposition, as shown in Table 7. 


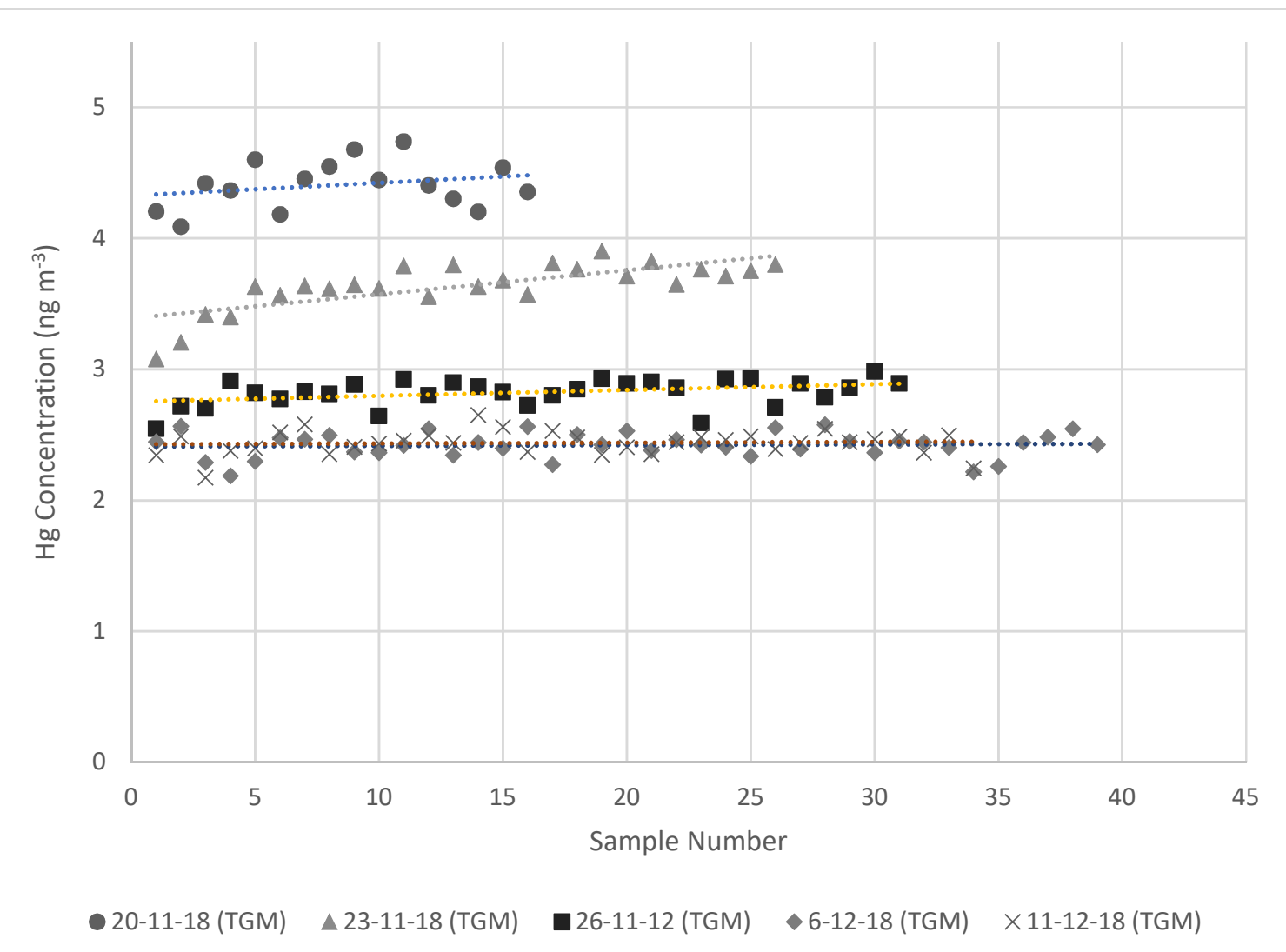

Figure 8: Time series of $\mathrm{Hg}$ measured by the Tekran 2537 Analyzer between 20 November -11 December 2018 at a flow rate of $5 \mathrm{~L} / \mathrm{min}$ and source temperature of $5^{\circ} \mathrm{C}$ while degassing previously adsorbed $\mathrm{Hg}$ 
Table 7: Average measured $\mathrm{Hg}$ concentration from the GOM source at a source temperature set point of $5^{\circ} \mathrm{C}$ and a flow rate of $5 \mathrm{~L} / \mathrm{min}$, before and after the GOM source was moved to an insulated container

\begin{tabular}{|c|c|c|}
\hline Date & $\mathrm{Hg}$ Concentration $\pm \mathrm{s}\left(\mathrm{ng} \mathrm{m}^{-3}\right)$ & RSD (\%) \\
\hline 17-Oct & $1.20 \pm 0.10$ & 8.56 \\
\hline 19-Oct & $1.16 \pm 0.12$ & 10.8 \\
\hline 24-Oct & $1.06 \pm 0.10$ & 9.39 \\
\hline Total Pre-Adjustment & $1.14 \pm 0.12$ & 10.8 \\
\hline $6-\mathrm{Dec}$ & $2.42 \pm 0.01$ & 3.99 \\
\hline 11-Dec & $2.44 \pm 0.09$ & 3.86 \\
\hline 12-Dec & $2.25 \pm 0.12$ & 5.47 \\
\hline 13-Dec & $2.27 \pm 0.13$ & 5.89 \\
\hline 14-Dec & $2.30 \pm 0.13$ & 3.72 \\
\hline Total Post-Adjustment & $2.34 \pm 0.13$ & 5.53 \\
\hline
\end{tabular}

In addition to the increase in the measured source concentration, there is also a decrease in the coefficient of variation, with the datasets measured prior to the source relocation ranging between $8.56-10.8 \%$, while the datasets measured after the source relocation ranged between $3.72-5.89 \%$. Comparing the average coefficient of variation to those presented in Table 9, which range from $8-14 \%$, an improvement is also evident. The source relocation also eliminated the temporal trend visible in all previous data sets, as shown in the time series of Figure 9. 


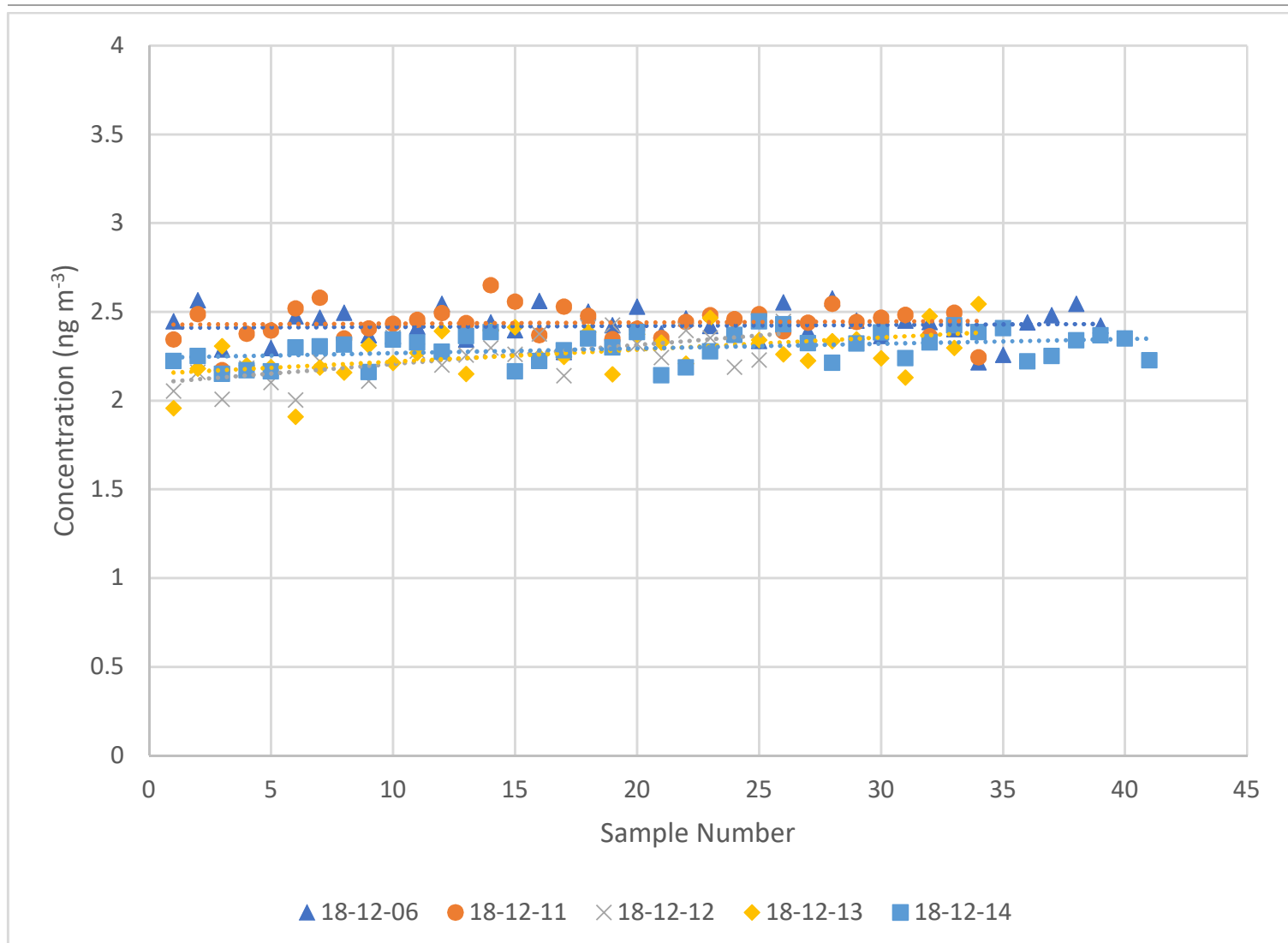

Figure 9: Time Series of $\mathrm{Hg}$ emitted from the GOM source, at a temperature of $5^{\circ} \mathrm{C}$ and a flow rate of $5 \mathrm{~L} / \mathrm{min}$. 


\subsection{Mathematical Modelling of the GOM Source Emission rate}

Over the period of 12 June to 31 August 2018, the $\mathrm{Hg}$ vapour generated from the GOM source was measured under controlled and varying conditions, to determine what, if any, mathematical relationship existed between the control variables and the resulting concentration. The conditions included flow rates of 1 , 5,7 , and $9.52 \mathrm{~L} / \mathrm{min}$, and temperature setpoints of $5,7.5$, and $10^{\circ} \mathrm{C}$. A summary of the complete dataset is listed in Table $\mathbf{8}$, and a summary of each combination is included in Table 9. The data indicates that increasing source temperature results in increased measured source concentration, and that increasing flow rate results in decreased source concentration. Using a custom script in $\mathrm{R}$, a multiple regression analysis was carried out, and the predicted concentration values were compared with the actual measured values. 
Table 8: Daily average emission rate measured from the GOM source following operating condition optimization.

\begin{tabular}{|r|r|r|r|r|r|r|}
\hline $\begin{array}{r}\text { Flow } \\
\text { Rate } \\
(\text { L/min) }\end{array}$ & $\begin{array}{r}\text { Temp } \\
\left({ }^{\circ} \mathrm{C}\right)\end{array}$ & $\begin{array}{r}\text { Date } \\
\text { Emission rate } \\
(\mathrm{pg} / \mathrm{s})\end{array}$ & $\mathrm{s}$ & $\mathrm{RSD}$ & $\mathrm{n}$ \\
\hline 9.52 & 7.5 & $6 / 25 / 2018$ & 0.176 & 0.014 & 7.8 & 41 \\
\hline 9.52 & 7.5 & $6 / 26 / 2018$ & 0.168 & 0.011 & 6.5 & 33 \\
\hline 9.52 & 7.5 & $6 / 27 / 2018$ & 0.169 & 0.014 & 8.0 & 60 \\
\hline 9.52 & 7.5 & $6 / 28 / 2018$ & 0.181 & 0.017 & 9.6 & 49 \\
\hline 7 & 10 & $7 / 23 / 2018$ & 0.0806 & 0.0038 & 4.8 & 47 \\
\hline 7 & 10 & $7 / 24 / 2018$ & 0.0831 & 0.0036 & 4.4 & 47 \\
\hline 7 & 10 & $8 / 23 / 2018$ & 0.0836 & 0.0062 & 7.4 & 47 \\
\hline 7 & 10 & $8 / 24 / 2018$ & 0.113 & 0.0096 & 8.5 & 48 \\
\hline 7 & 7.5 & $7 / 26 / 2018$ & 0.106 & 0.011 & 10.4 & 48 \\
\hline 7 & 7.5 & $7 / 27 / 2018$ & 0.0998 & 0.013 & 12.6 & 51 \\
\hline 7 & 7.5 & $7 / 30 / 2018$ & 0.178 & 0.012 & 6.7 & 44 \\
\hline 7 & 7.5 & $8 / 2 / 2018$ & 0.184 & 0.014 & 7.5 & 42 \\
\hline 7 & 7.5 & $8 / 16 / 2018$ & 0.151 & 0.013 & 8.7 & 40 \\
\hline 7 & 7.5 & $8 / 17 / 2018$ & 0.137 & 0.0098 & 7.1 & 45 \\
\hline 7 & 5 & $7 / 17 / 2018$ & 0.160 & 0.013 & 8.1 & 39 \\
\hline 7 & 5 & $7 / 18 / 2018$ & 0.134 & 0.010 & 7.5 & 37 \\
\hline 7 & 5 & $7 / 19 / 2018$ & 0.145 & 0.0147 & 10.1 & 61 \\
\hline 7 & 5 & $8 / 20 / 2018$ & 0.167 & 0.019 & 11.5 & 45 \\
\hline 7 & 5 & $8 / 21 / 2018$ & 0.0832 & 0.0041 & 5.0 & 45 \\
\hline 5 & 10 & $8 / 27 / 2018$ & 0.0906 & 0.0088 & 9.7 & 41 \\
\hline 5 & 10 & $8 / 28 / 2018$ & 0.141 & 0.0082 & 5.8 & 44 \\
\hline 5 & 7.5 & $7 / 3 / 2018$ & 0.134 & 0.0095 & 7.1 & 38 \\
\hline 5 & 7.5 & $7 / 4 / 2018$ & 0.158 & 0.016 & 10.2 & 48 \\
\hline 5 & 7.5 & $7 / 5 / 2018$ & 0.146 & 0.016 & 11.0 & 44 \\
\hline 5 & 7.5 & $8 / 13 / 2018$ & 0.115 & 0.011 & 10.0 & 64 \\
\hline 5 & 7.5 & $8 / 14 / 2018$ & 0.110 & 0.013 & 12.1 & 47 \\
\hline 1 & 7.5 & $7 / 9 / 2018$ & 0.106 & 0.011 & 10.1 & 48 \\
\hline 1 & 7.5 & $7 / 10 / 2018$ & 0.141 & 0.014 & 10.2 & 38 \\
\hline 1 & 7.5 & $7 / 11 / 2018$ & 0.159 & 0.019 & 11.9 & 56 \\
\hline 1 & 7.5 & $7 / 12 / 2018$ & 0.181 & 0.013 & 7.4 & 49 \\
\hline 1 & 7.5 & $8 / 7 / 2018$ & 0.187 & 0.012 & 6.4 & 53 \\
\hline 1 & 7.5 & $8 / 10 / 2018$ & 0.0876 & 0.0045 & 5.1 & 46 \\
\hline 1 & 5 & $8 / 30 / 2018$ & 0.0764 & 0.0029 & 3.8 & 61 \\
\hline 1 & 5 & $8 / 31 / 2018$ & 0.0995 & 0.0063 & 6.4 & 56 \\
\hline & & & & & & \\
\hline
\end{tabular}


Table 9: Source emission rates measured at each flow rate and temperature combination during the sampling campaign

\begin{tabular}{|l|l|l|l|l|r|r|}
\hline $\begin{array}{l}\text { Set } \\
\text { Point } \\
\left({ }^{\circ} \mathrm{C}\right)\end{array}$ & $\begin{array}{l}\text { Flow } \\
\text { Rate } \\
(\mathrm{L} / \mathrm{min})\end{array}$ & $\mathrm{n}$ & $\begin{array}{l}\text { Source } \\
\text { Concentration } \\
\left(\mathrm{ng} / \mathrm{m}^{3}\right) \pm \mathrm{s}\end{array}$ & $\begin{array}{l}\text { Emission Rate } \\
(\mathrm{pg} / \mathrm{s}) \pm \mathrm{s}\end{array}$ & Residuals & $\begin{array}{l}\text { Relative } \\
\text { Residuals } \\
(\%)\end{array}$ \\
\hline 5.0 & 1 & 117 & $4.950 \pm 0.41$ & $0.0826 \pm 0.0068$ & 0.0111 & 12.9 \\
\hline 5.0 & 7 & 227 & $0.9166 \pm 0.10$ & $0.0153 \pm 0.0018$ & -0.00128 & -9.91 \\
\hline 7.5 & 1 & 290 & $5.165 \pm 0.50$ & $0.0861 \pm 0.0083$ & -0.00332 & -4.76 \\
\hline 7.5 & 5 & 241 & $1.782 \pm 0.22$ & $0.0297 \pm 0.0036$ & 0.00303 & 8.91 \\
\hline 7.5 & 7 & 270 & $1.209 \pm 0.16$ & $0.0202 \pm 0.0027$ & -0.000576 & -4.83 \\
\hline 7.5 & 9.52 & 183 & $1.091 \pm 0.09$ & $0.0182 \pm 0.0016$ & 0.00173 & 8.80 \\
\hline 10.0 & 5 & 86 & $2.200 \pm 0.16$ & $0.0367 \pm 0.0026$ & 0.00344 & 8.87 \\
\hline 10.0 & 7 & 189 & $1.415 \pm 0.20$ & $0.0236 \pm 0.0032$ & -0.00226 & -11.9 \\
\hline
\end{tabular}

A variety of potential independent variables were screened for the regression model, but ultimately the only significant variables were found to be source flow rate and source temperature. According to the Clausius-Clapeyron equation, vapour pressure increases with temperature according to an equation of the form $\log (y)=b-a x^{-1}$, where $y$ is partial vapour pressure, and $x$ is temperature. An increased partial vapour pressure of $\mathrm{HgCl}_{2}$ indicates an increased quantity of $\mathrm{HgCl}_{2}$ in the vapour phase, and consequently a higher source concentration. As it was unknown what the relationship is between flow rate and source concentration, it was assumed that a linear model is no worse than any other model. Consequently, the data was transformed by taking the natural logarithm of source concentration and the reciprocal of temperature set point, resulting in a linear relationship between the two, as well as taking the natural logarithm of flow rate (if there is a linear relationship between flow rate and source concentration, there will also be a linear relationship between the 
natural logarithms of both of those variables). The resulting equation for the source vapour concentration at flow rates between $1-9.52 \mathrm{~L} / \mathrm{min}$, and source temperatures between $5-10^{\circ} \mathrm{C}$ is as follows:

$$
\operatorname{Ln}\left(\mathrm{HgCl}_{2} \frac{1}{n g \mathrm{~m}^{-3}}\right)=22.56-0.7512 \times \operatorname{Ln}\left(\text { Flow rate } \frac{1}{\mathrm{Lmin}^{-1}}\right)-\frac{7009}{T K^{-1}}
$$




\subsection{Determination of Species Distribution of the GOM Source}

As described in section 1.4, GOM sources described in the literature have been reported to emit both GOM and GEM, with the GOM fraction ranging from as high as $97.1 \%$, to as low as $72 \% .5,17,18,22,29,32$ To determine the GOM fraction of the source in this study, a quartz tube, packed with $\mathrm{KCl}$-coated quartz chips was initially used as a GOM trap (later it was determined that the $\mathrm{KCl}$-coating was unnecessary). Due to the high level of 'stickiness', and its affinity for $\mathrm{KCl}$, GOM is selectively captured by the GOM trap, while allowing the passage of GEM. The procedure from section 2.3 was repeated under several conditions, which are tabulated in Table 10. In several of the trials, the presumed GEM level was below the manufacturer's reported detection limit of the Tekran 2537 analyzer $\left(0.10 \mathrm{ng} \mathrm{m}^{-3}\right)$. In these cases, the data points below the detection limit were set to $0.10 \mathrm{ng} \mathrm{m}^{-3}$ prior to the calculation of the GOM fraction, to determine the minimum estimate of the GOM fraction. The results indicate that the GOM fraction is lowest under the experimental conditions of a flow rate of $1 \mathrm{~L} \mathrm{~min}^{-1}$, and a source temperature of $7.5^{\circ} \mathrm{C}(61.3-64.2 \%)$. The GOM fraction is highest under the experimental conditions of a flow rate of $5 \mathrm{~L} \mathrm{~min}-1$, and a source temperature of $5^{\circ} \mathrm{C}(83.0-87.9 \%)$.

It seems notable that the lowest calculated GOM fraction corresponds with the highest TGM concentration, which might suggest sample loss to the walls of the sampling line (due to the stickiness of GOM) is responsible for the lower detected GOM fraction. As discussed in section 3.3, it is clear that some amount of $\mathrm{Hg}$ deposition takes place to the walls of the tubing downstream of the source, 
and it would be expected that more deposition would take place when the flow rate is low and that the closer the $\mathrm{Hg}$ vapour temperature is to the temperature of the tubing (i.e. room temperature), the more deposition would take place. This can be seen by comparing the data collected at a flow rate of $7 \mathrm{~L} / \mathrm{min}$ and source temperature of $7.5^{\circ} \mathrm{C}$, which have a resulting concentration of $1.15 \mathrm{ng} \mathrm{m}^{-3}$, to the data collected at a flow rate of $5 \mathrm{~L} / \mathrm{min}$ and $5^{\circ} \mathrm{C}$, which have a resulting concentration of $1.14 \mathrm{ng} \mathrm{m}^{-3}$. As expected, less GOM was detected under the combination of conditions with a temperature setting closer to room temperature due to the loss of GOM through deposition.

Table 10: Source conditions and Hg species of the GOM source

\begin{tabular}{|l|l|l|l|l|}
\hline Date & $\begin{array}{l}\text { Source Flow } \\
\text { Rate }\left(\mathrm{L} \mathrm{min}^{-1}\right)\end{array}$ & $\begin{array}{l}\text { Source } \\
\text { Temperature }\left({ }^{\circ} \mathrm{C}\right)\end{array}$ & $\begin{array}{l}\text { Source TGM } \\
\text { Concentration } \\
\left(\mathrm{ng} \mathrm{m}^{-3}\right)\end{array}$ & $\begin{array}{l}\text { GOM Fraction } \\
(\%)\end{array}$ \\
\hline $18-07-31$ & 7 & 7.5 & 1.15 & 72.8 \\
\hline $18-08-01$ & 7 & 7.5 & 1.15 & 75.7 \\
\hline $18-08-08$ & 1 & 7.5 & 5.96 & 64.2 \\
\hline $18-08-09$ & 1 & 7.5 & 5.43 & 61.3 \\
\hline $18-10-25$ & 5 & 5 & 1.14 & 87.5 \\
\hline $18-10-26$ & 5 & 5 & 1.14 & 87.9 \\
\hline $18-10-30$ & 5 & 5 & 1.14 & 83.0 \\
\hline
\end{tabular}




\subsection{Impact of 2019 Source Contamination on GOM Source Measurements}

Following a two-week shutdown of the system between December 2018 January 2019 , the system became contaminated and needed to be cleaned. Following this decontamination procedure, it was found that the measured concentration of $\mathrm{Hg}$ in the GOM source air had increased by approximately two orders of magnitude, from concentrations on the order of $1-7 \mathrm{ng} \mathrm{m}^{-3}$, to concentrations on the order of $300-500 \mathrm{ng} \mathrm{m}^{-3}$. Replacing every component of the GOM source line, including the source itself, with equivalent components made no meaningful improvement to the situation. Consequently, the working hypothesis that was adopted was that the $\mathrm{Hg}$ species within the previous source vial, which had been stored for a lengthy period of time without being disturbed, had become passivated in some fashion, resulting in the low measurements that had been observed. The agitation of the source vial during the decontamination of the system resulted in a mixing of the passivated surface layer with the nonpassivated bulk solid, resulting in the higher measurements seen, while the replacement source vial contained fresh $\mathrm{HgCl}_{2}$, and emitted similar levels of GOM. As a result, the "new" state of the system was treated as the accurate state-the previous state the anomaly. An additional issue was that a significant background level of $\mathrm{Hg}$ was present throughout the analysis (due to the earlier contamination), despite systematic efforts to remove it. Since the elevated background values were consistent, work was continued to determine what relationship existed between the source concentration and the source temperature (due to the high levels of GOM present, the source was only 
operated at a flow rate of $1 \mathrm{~L} / \mathrm{min}$ ) and to establish what fraction of $\mathrm{Hg}$ emitted from the source was present as GOM.

3.6.1 Determination of the effect of GOM source temperature on source emission rate

Using the method described in section 2.2.3.2, the emission rate of $\mathrm{Hg}$ from the GOM source was estimated at several temperatures (ranging from $15^{\circ} \mathrm{C}$ to $5^{\circ} \mathrm{C}$ ), using a series of spikes to generate a calibration curve. The doseresponse curves generated are shown in Figure 10.

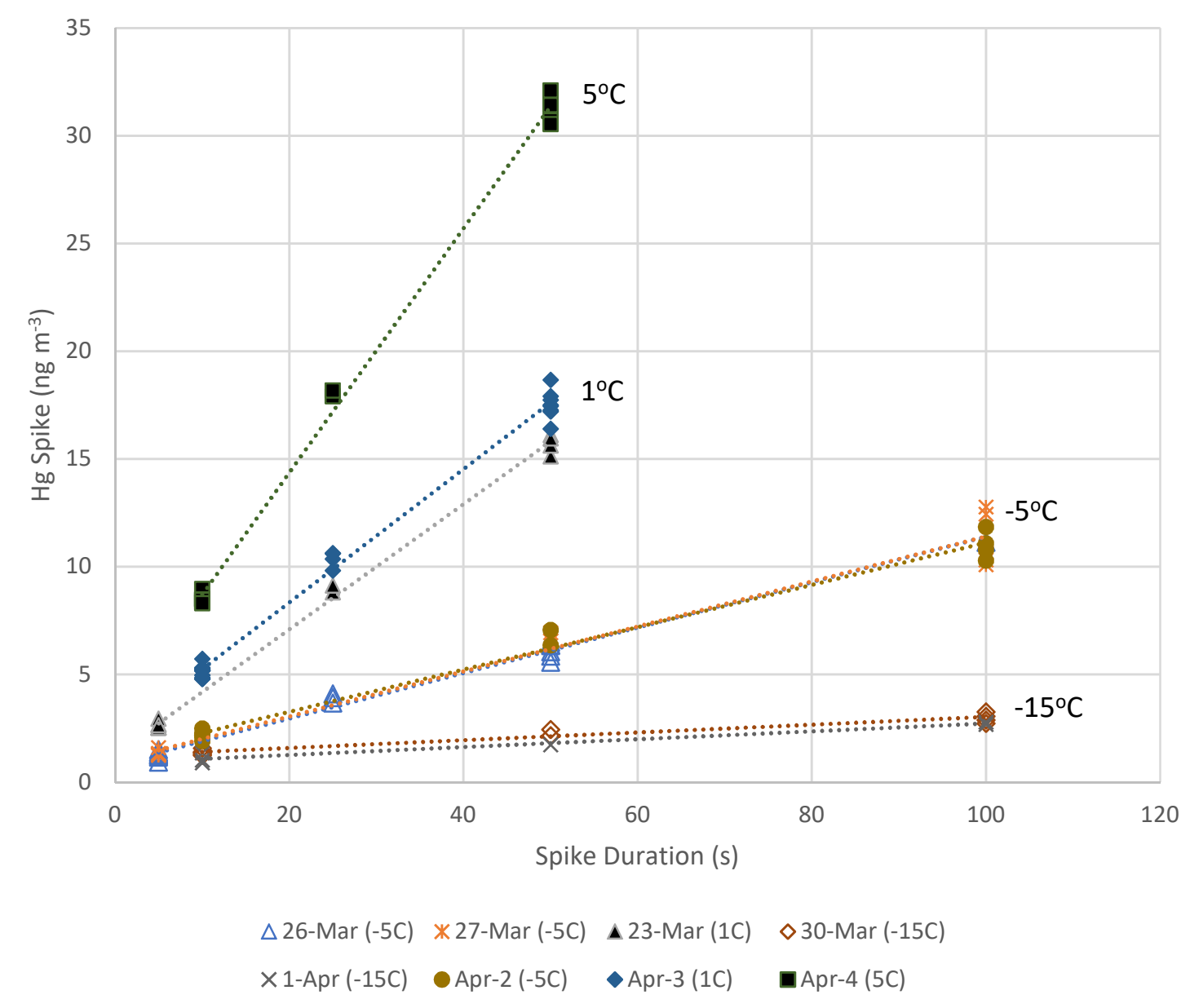

Figure 10: Dose-Response curves for the GOM source at a flow rate of $1 \mathrm{~L} / \mathrm{min}$, and source temperature set point ranging between $-15^{\circ} \mathrm{C}$ to $5^{\circ} \mathrm{C}$. 
In an individual dose-response curve, replicate measurements were made (3-1-2 at each point), and each of these dose-response curves was then carried out in triplicate on an individual sampling day. Measurements were carried out in two phases, in the first, vapour from the source was analyzed as the source temperature was decreased over the course of a week, with days in between measurements being needed for the system to return to a steady state. In the second phase, measurements were made as the source temperature was increased day-to-day, with 16 hours of equilibration time (rather than 30-40 hours as in the previous method.) In general, there was good agreement between these two sets of measurements, indicating that the source can quickly reestablish its steady-state if the concentration is being increased rather than decreased.

Using the calculated emission rates, the temperature dependence of the source emission rate was determined, as shown in Figure 11. A summary of the dataset is tabulated in Table 11. As discussed in section 3.4 a logarithmic transformation of the data was carried out prior to the regression analysis. The resulting equation is $\ln \left(\right.$ Emission Rate $\left.\frac{1}{\mathrm{pg} / \mathrm{s}}\right)=48.883-\frac{13339}{T K^{-1}}$. The coefficient of determination of 0.997 indicates that the source temperature has a strong and consistent relationship with the emitted source vapour, which confirms that the temperature dependence of $\mathrm{HgCl}_{2}$ 's vapour pressure is directly related to the $\mathrm{Hg}$ emission rate. Additionally, if one contrasts the tabulated data from Table 11 to the previously collected data tabulated in Table $\mathbf{9}$, it is evident that the coefficient of variation is lower on average (between $0.74-7.77 \%$ rather than $7.04-$ 
$13.8 \%)$, indicating that the source performance was improved relative to its previous state.

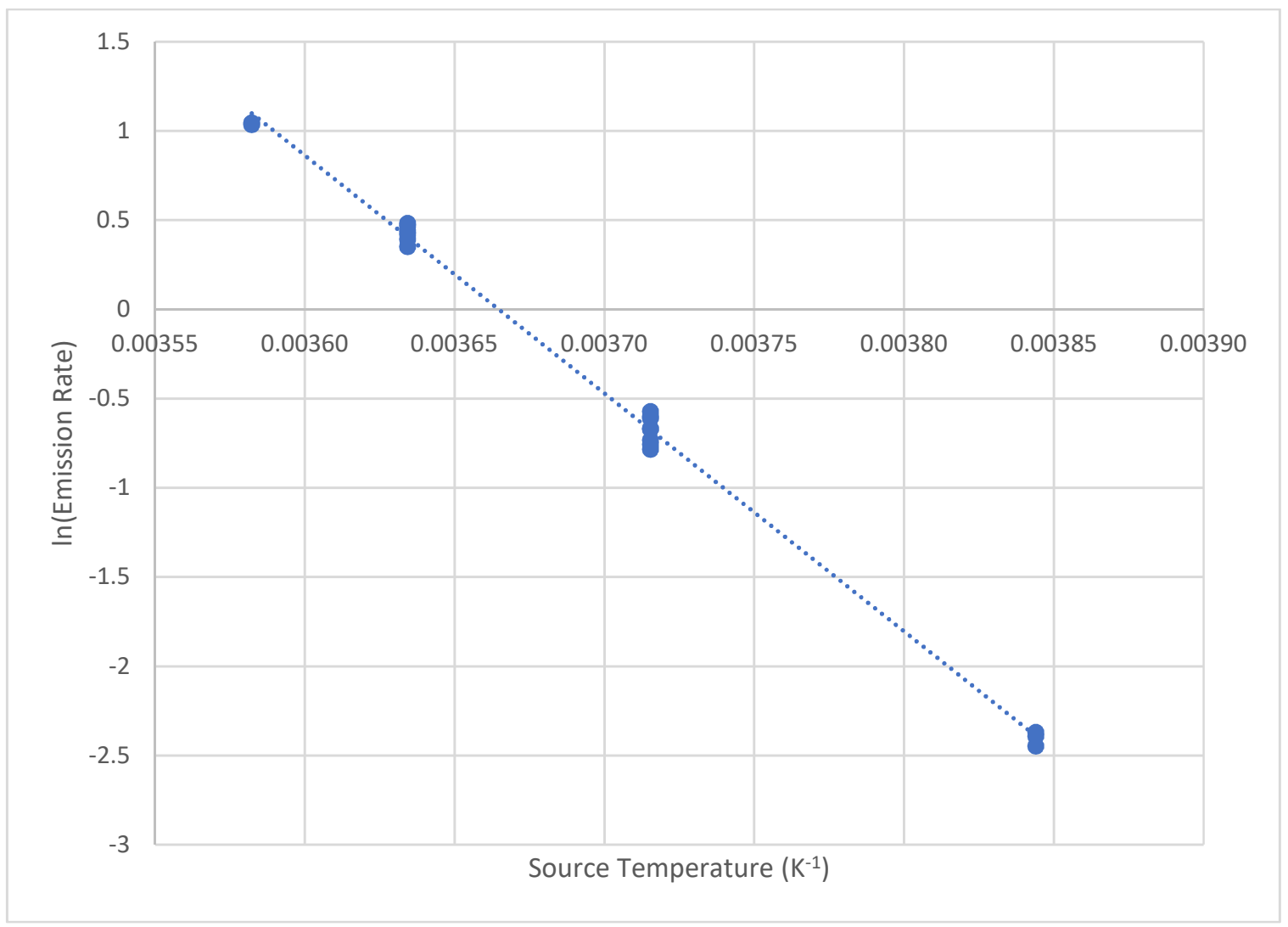

Figure 11: Dependence of the source $\mathrm{Hg}$ emission rate on source temperature

Table 11: Summary of the GOM source emission rate over the temperature range of $-13-6$ ${ }^{\circ} \mathrm{C}$

\begin{tabular}{|c|c|c|c|c|}
\hline $\begin{array}{l}\text { Source } \\
\text { Temperature }\left({ }^{\circ} \mathrm{C}\right)\end{array}$ & $\begin{array}{l}\text { Source Emission } \\
\text { Rate }(\mathrm{pg} / \mathrm{s}) \pm \mathrm{s}\end{array}$ & $\begin{array}{l}\text { Coefficient of } \\
\text { Variation (\%) }\end{array}$ & Residuals (\%) & $n$ \\
\hline 6 & $2.83 \pm 0.021$ & 0.74 & 0.43 & $2^{*}$ \\
\hline 2 & $1.53 \pm 0.074$ & 4.80 & -3.82 & 6 \\
\hline-4 & $0.511 \pm 0.040$ & 7.77 & 3.80 & 8 \\
\hline-13 & $0.0905 \pm 0.0036$ & 3.98 & -3.94 & 3 \\
\hline
\end{tabular}

* One sample was rejected as an outlier following a Q-test. 


\subsubsection{Determination of the species distribution of the GOM source}

Speciation analysis was carried out on the $\mathrm{Hg}$ emitted from the source,

using the procedure described in section 2.3.3. Additionally, attempts were made to recover the trapped GOM from the GOM trap, but the background level of $\mathrm{Hg}$ in the system was too high for any meaningful data to be collected, as the quantity of $\mathrm{Hg}$ present in the trap because of continuing system contamination was significantly higher than the quantity of $\mathrm{Hg}$ spiked into the system. The results from several experimental trials are tabulated in Table 12.

Table 12: GOM fraction of the GOM source vapour calculated by difference, with a correction factor applied for the estimated level of trapped GEM

\begin{tabular}{|l|l|l|l|l|l|}
\hline Date & $\begin{array}{l}\text { Source } \\
\text { Temperature } \\
\left({ }^{\circ} \mathrm{C}\right)\end{array}$ & $\mathrm{Hg}_{(0)}\left(\mathrm{ng} \mathrm{m}^{-3}\right)$ & $\begin{array}{l}\text { Corrected } \\
\left(\mathrm{est.}^{-} \mathrm{Hg}_{(0)}\right. \\
\left(\mathrm{ng} \mathrm{m}^{-3}\right)\end{array}$ & TGM $\left(\mathrm{ng} \mathrm{m}^{-3}\right)$ & $\begin{array}{l}\text { GOM } \\
\text { fraction (\%) }\end{array}$ \\
\hline 19-Mar $(\mathrm{a})$ & 6 & 2.131 & 3.196 & 30.54 & 89.5 \\
\hline 19-Mar $\left(b^{*}\right)^{*}$ & 6 & 3.240 & 3.240 & 30.54 & 89.4 \\
\hline 20-Mar & 6 & 2.071 & 3.106 & 28.74 & 89.2 \\
\hline 23-Mar & 2 & 2.630 & 3.945 & 22.71 & 82.6 \\
\hline 29-Mar & -13 & 4.507 & 6.761 & 41.31 & 83.6 \\
\hline 1-Apr & -13 & 1.112 & 1.668 & 7.977 & 79.1 \\
\hline
\end{tabular}

${ }^{*}$ In 19-Mar(b), the primary pyrolyzer was cooled to room temperature and would not be expected to trap the same fraction of GEM as it would otherwise.

An injection port was temporarily installed upstream of the pyrolyzer, to determine whether GEM would be trapped on either of the two pyrolyzers.

Replicate injections upstream of the pyrolyzer resulted in a background corrected measured concentration of $8.19 \mathrm{ng} \mathrm{m}^{-3}$, while an injection made directly into the Tekran injection port resulted in a background corrected measured concentration of $12.28 \mathrm{ng} \mathrm{m}^{-3}$, indicating that the GOM traps captured as much as $1 / 3$ of the GEM that passed through them. An injection downstream of the GOM traps 
resulted in no significant difference from the injection into the Tekran injection port. This factor was used to correct the estimated GEM value.

The tests carried out between $-13-6^{\circ} \mathrm{C}$ indicate a GOM fraction between $77.0 \%$ and $89.5 \%$, while the quantity of THg spiked varied between $4.418-$ $41.31 \mathrm{ng} \mathrm{m}^{-3}$. This is consistent with literature reports that the GOM fraction of vapour emitted decreases as temperature decreases..$^{22}$ This data is also significantly more consistent than the previously collected measurements in which the GOM fractions ranged from $65-87 \%$, despite a much larger range in both air-stream concentrations and source temperature settings in this case compared to the previous case.

\subsubsection{Evaluation of the Source at flow rates in excess of $1 \mathrm{~L} / \mathrm{min}$}

Due to the excessively high levels of $\mathrm{Hg}$ emitted from the system, it was not practical to evaluate the source at a temperature of $5^{\circ} \mathrm{C}$ and a flow rate in excess of $1 \mathrm{~L} / \mathrm{min}$. However, with a source temperature of $-15^{\circ} \mathrm{C}$, the resulting source concentration was approximately $5-10 \mathrm{ng} \mathrm{m}^{-3}$, which was sufficiently low to be practical for continuous analysis. Consequently, measurements were carried out at a source temperature setting of $-15^{\circ} \mathrm{C}$ and a flow rate of $5 \mathrm{~L} / \mathrm{min}$. The results are shown in Figure 12. 


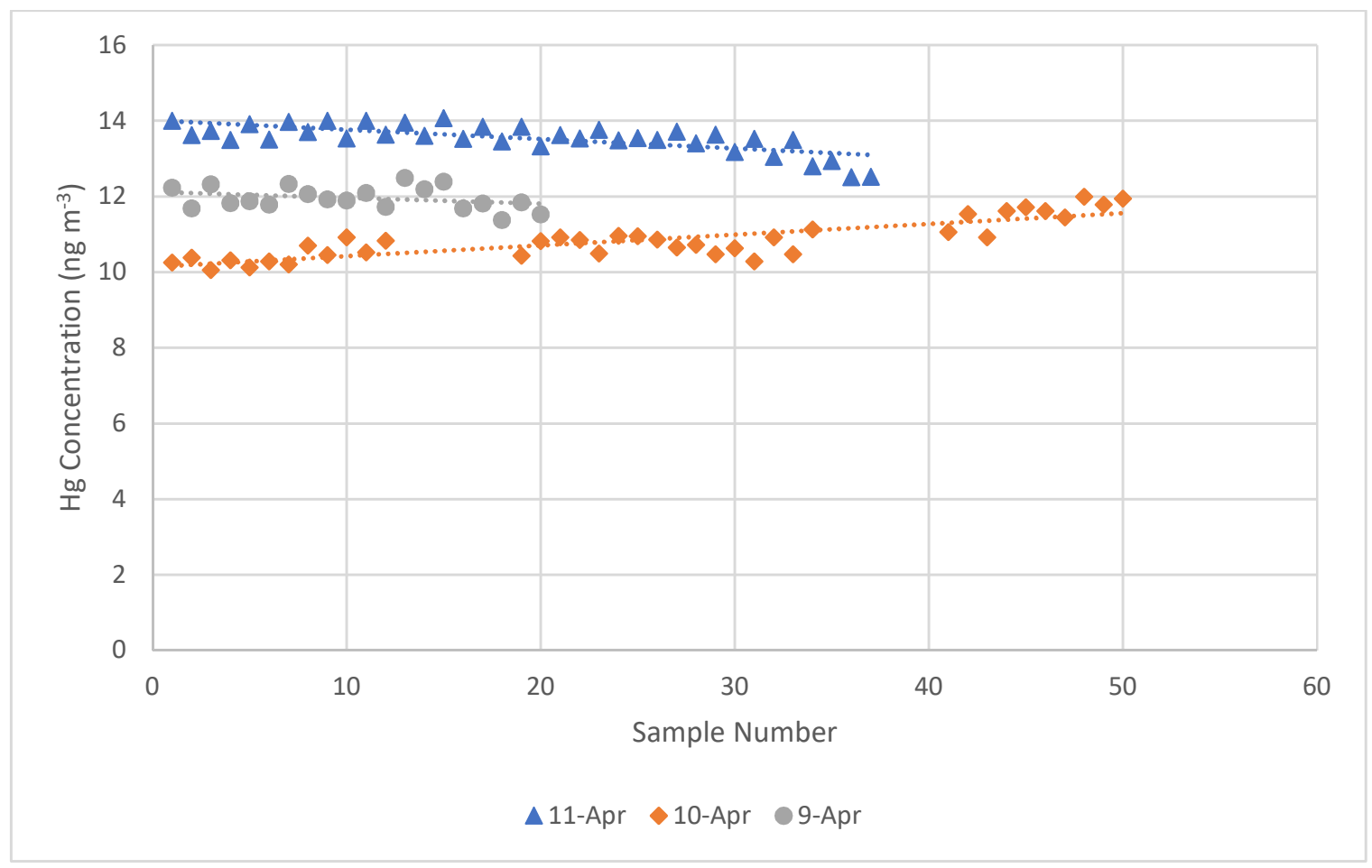

Figure 12: Time Series of GOM source measurements at a flow rate of $5 \mathrm{~L} / \mathrm{min}$ and a source temperature setting of $-15^{\circ} \mathrm{C}$ on three consecutive days

As can be seen from the data, the measurements at an increased flow rate resulted in not only very inconsistent measurements, but also resulted in an increase in measured concentration relative to the measurements made at $-15^{\circ} \mathrm{C}$ and $1 \mathrm{~L} / \mathrm{min}$, rather than a decrease as has been previously observed. The cause of the concentration increase is that the cooling system is inefficient at cooling the incoming air at higher flow rates, as shown in Figure 13. Consequently, while increasing flow rate resulted in an effective dilution of the source airflow, the increased source temperature increased concentration at a rate higher than the rate at which the concentration was decreased via dilution. 


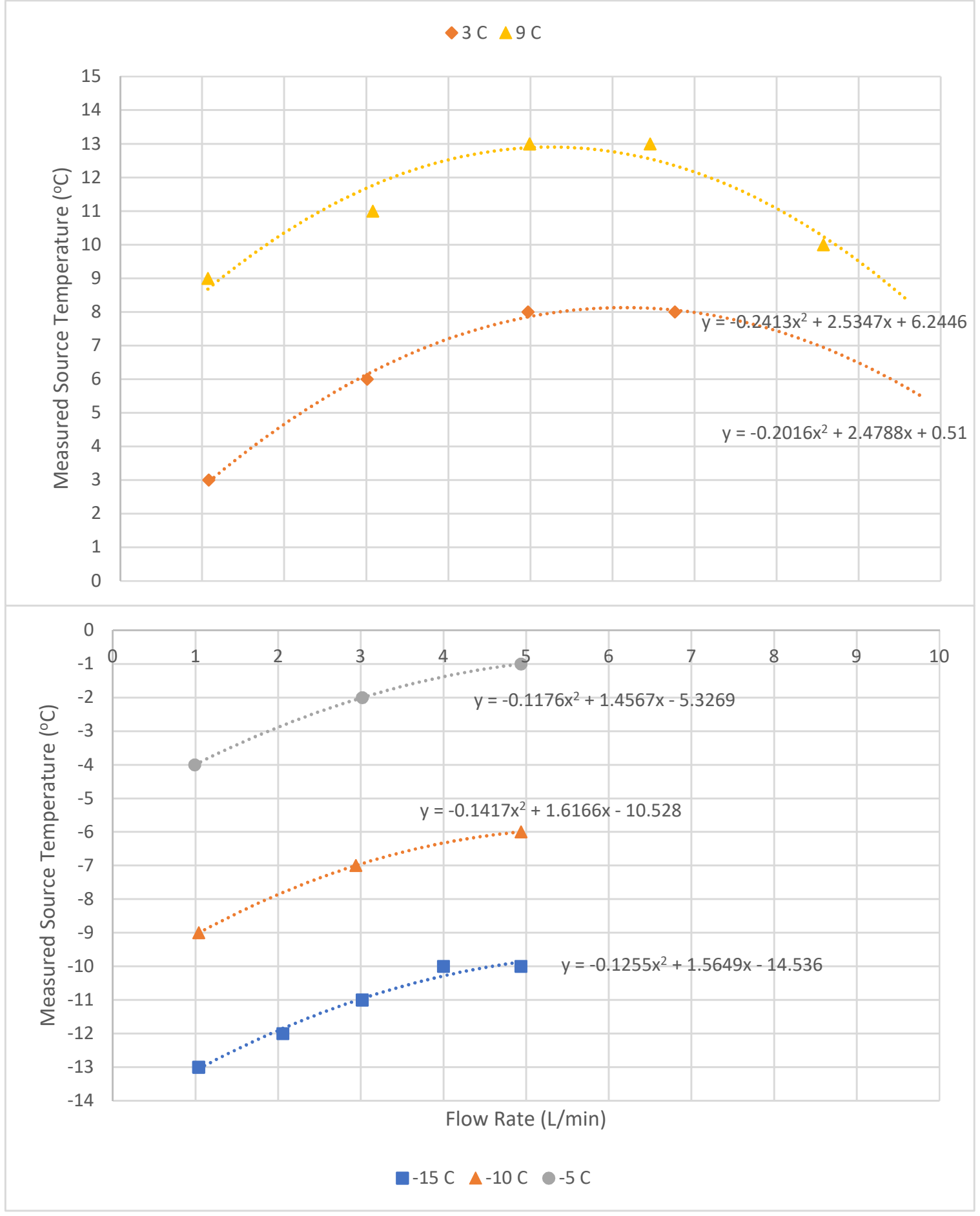

Figure 13: Measured source temperature at flow rates between $1-7 \mathrm{~L} / \mathrm{min}$, and liquid bath set points between $-15-9^{\circ} \mathrm{C}$. The curves in the upper panel are measured using a copper coil $5 \mathrm{~m}$ in length, while the curves in the lower panel are measured using a copper coil 10 $m$ in length 
As this combination of operating conditions resulted in less consistent data at a higher resulting source concentration than the previous conditions of $1 \mathrm{~L} / \mathrm{min}$, $15^{\circ} \mathrm{C}$, no further work was carried out at flow rates in excess of $1 \mathrm{~L} / \mathrm{min}$.

\subsubsection{Inter-comparison of GOM source vials 1 and 2}

Following the preceding analysis, efforts were undertaken to compare the GOM emission rate from both the original vial (vial 1) and the replacement vial (vial 2) at consistent sampling conditions. An initial complication was introduced due to GOM vial 1 having contaminated itself and its sampling flask due to improper storage measures, and vial 2 also having contaminated itself when it was stored in the same way while vial 1 was being used for analysis (prior to realizing that said contamination had taken place). This situation was largely remedied, ultimately via soaking the source flask with stannous chloride to reduce adsorbed $\mathrm{HgCl}_{2}$ to elemental mercury and treating the outside of the GOM source vial with stannous chloride as well. As the source vials couldn't be soaked in stannous chloride in the same fashion as the flask had been, both vials were subsequently wrapped in parafilm wax to minimize any degassing of GOM that remained on the surfaces. In general, it would be preferred to discard the $\mathrm{HgCl} 2$ within the source vials and thoroughly soak them, but the objective of this experiment was to compare specifically the vial used during 2018 and its 2019 replacement. Consequently, replacing the vials with what effectively would have been two "new" vials would not have achieved the desired purpose. The experiment was carried out using the method described in section 3.6.1, at a flow rate of $1 \mathrm{~L} / \mathrm{min}$, and a source temperature set point of $-15^{\circ} \mathrm{C}$ for $\mathrm{GOM}$ vial 1 , and $12--13^{\circ} \mathrm{C}$ for GOM vial 2. A higher temperature was used for GOM vial 2 due to 
an equipment failure preventing it from being cooled to the appropriate temperature. However, both vials were able to be compared to the previous data presented in section 3.6.1, to determine whether any difference existed between the two source vials' Hg emission rate. The dose-response curves collected are shown in Figure 14, and the comparison of both vials' Hg emission rates to those calculated using the calibration curve from section 3.6.1 are tabulated in Table 13.

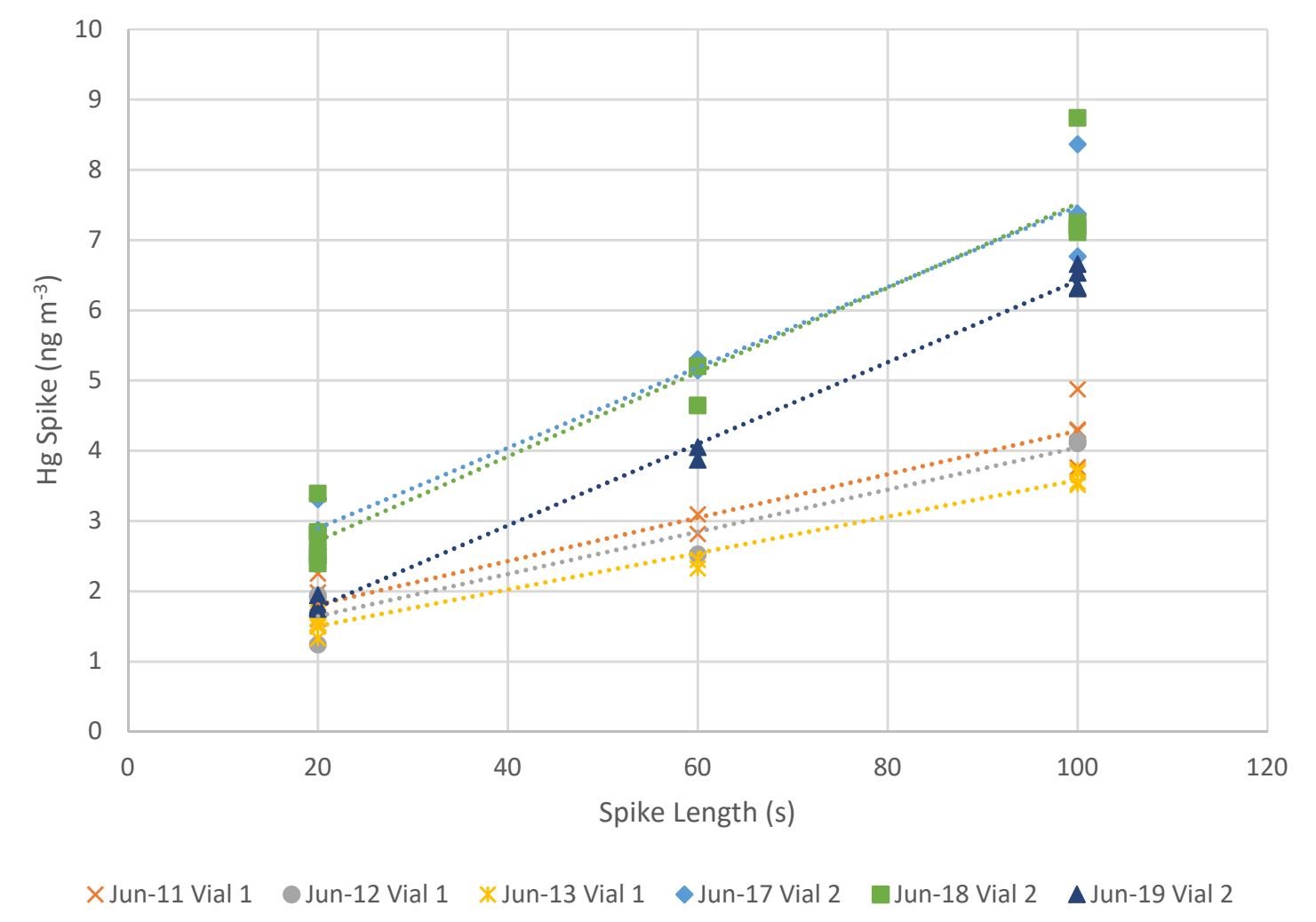

Figure 14: Dose response curves for GOM vial 1 and GOM vial 2 at a flow rate of $1 \mathrm{~L} / \mathrm{min}$, and a source temperature setting of $-15^{\circ} \mathrm{C}$ for GOM Vial 1, and a source temperature setting of $-13--12^{\circ} \mathrm{C}$ for GOM Vial 2. 
Table 13: Comparison of the measured $\mathrm{Hg}$ emission rates from vials 1 and 2 to the predicted emission rates from the calibration curve.

\begin{tabular}{|c|c|c|c|c|}
\hline Vial & $\begin{array}{l}\text { Temperature } \\
\text { Setpoint }\left({ }^{\circ} \mathrm{C}\right)\end{array}$ & $\begin{array}{l}\text { Emission rate } \\
(\mathrm{pg} / \mathrm{s})\end{array}$ & $\begin{array}{l}\text { Calculated Emission } \\
\text { rate }(\mathrm{pg} / \mathrm{s})\end{array}$ & $\begin{array}{l}\text { Relative Residual } \\
\text { (\%) }\end{array}$ \\
\hline Vial 1 & -15 & $0.145 \pm 0.013$ & 0.0909 & 59.2 \\
\hline Vial 2 & $-13--12$ & $0.292 \pm 0.0069$ & 0.153 & 90.9 \\
\hline
\end{tabular}

Two conclusions can be drawn from the data presented in Table 13.

Firstly, it appears that the limited cleaning procedure carried out to remove $\mathrm{Hg}$ contamination from the vials was not entirely effective, as $\mathrm{Hg}$ vial 2 (which was used to generate the calibration curve previously) was calculated to emit $90.9 \%$ more $\mathrm{Hg}$ than would be expected based on the calibration curve. This is not entirely unexpected, as prior to the cleaning procedure the system generated as much as $3.5 \mathrm{pg} / \mathrm{s}$ of $\mathrm{Hg}\left(\right.$ at $\left.-15^{\circ} \mathrm{C}\right)$ from the contaminated surfaces alone, suggesting that if as little as $2.5 \%$ of the contaminated surface was left uncleaned, it could be responsible for the entire disparity between the calculated and actual emission rates for vial 2 . The second conclusion that can be drawn is that while vial 1 does not release $\mathrm{Hg}$ identically to vial 2 , it emits a very comparable quantity of $\mathrm{Hg}$, with vial 1 emitting $0.145 \mathrm{pg} / \mathrm{s}$ (with possible contamination), and vial 2 (previously) emitting $0.0905 \mathrm{pg} / \mathrm{s}$ at the same sampling conditions, a difference in absolute terms of approximately $0.05 \mathrm{pg} / \mathrm{s}$. It is thus conclusively determined that the measurements taken during 2018 were anomalous, rather than normal behavior. 


\subsection{Research outcome and implications}

\subsection{Accomplishments}

During this work, a GOM source was modified and evaluated for its ability to generate GOM-containing vapour at a relevant level for the calibration of GOM speciation systems (i.e. ambient levels). This source was unique due to using a low temperature between $-15-5^{\circ} \mathrm{C}$; and made use of a volumetric flow rate of 1 $\mathrm{L} / \mathrm{min}$, rather than a temperature significantly higher than room temperature, and a flow rate of $500 \mathrm{~mL} / \mathrm{min}$ or less that are more typical of literature GOM sources. The rationale for this choice of conditions was that a high volumetric flow rate (of at least $1 \mathrm{~L} / \mathrm{min}$, matching the flow rate of the Tekran 2537 analyzer) would eliminate the need for diluting the source vapour downstream of the source, and that maintaining the source below room temperature would result in both a low $\mathrm{Hg}$ emission rate, and minimize the quantity of $\mathrm{Hg}$ that would be lost to the sampling pathway due to condensation. The latter consideration was found to be effective at temperature differences of up to $25-35^{\circ} \mathrm{C}$, but it was ineffective for smaller temperature differences of $10-15^{\circ} \mathrm{C}$. The low temperature conditions were also validated as a means of controlling the source emission rate, with the source emission rate decreasing from $2.83 \mathrm{pg} / \mathrm{s}$ (approximately $170 \mathrm{ng} \mathrm{m}^{-3}$ ) at a source temperature of $6^{\circ} \mathrm{C}$, to an emission rate of $0.0905 \mathrm{pg} / \mathrm{s}$ (approximately $5-6$ $\mathrm{ng} \mathrm{m}^{-3}$ ) at a source temperature of $-13^{\circ} \mathrm{C}$.

When operated at a temperature of $-13^{\circ} \mathrm{C}$, with a source flow rate of 1 $\mathrm{L} / \mathrm{min}$, the source was found to emit $\mathrm{Hg}$ vapour at an environmentally relevant level of $0.0905 \mathrm{pg} / \mathrm{s}$. Replicate measurements indicated a good degree of reproducibility, with a small coefficient of variation across all datasets for a given 
sampling condition, both from replicate measurements conducted on a single day, and replicate measurements conducted on separate days. When continuous measurements were made, there was a significantly smaller coefficient of variation, of $1.3-5.5 \%$, which compares favourably to the continuous measurements from the 2018 dataset, in which coefficients of variation ranged between approximately $4-12 \%$ (Table 8 ), as well as the coefficients of variation for sources in the literature which reported a coefficient of variation, which range from $7.5 \%$ (Xiao et $\mathrm{al}^{18}$ ) to $8.9-16.6 \%$ (Feng et $\mathrm{al}^{29}$ )

The data was fitted to a linear regression model, the equation of that model is:

$$
\ln \left(\text { Emission Rate } \frac{1}{p g / s}\right)=48.883-\frac{13339}{T K^{-1}}
$$

The resulting coefficient of determination was 0.997 , indicating that the amount of $\mathrm{Hg}$ emitted from the source at different temperatures were consistent with one another.

Finally, using a GOM trap, the fraction of GOM in the source vapour was determined at several sampling conditions. Calculation by difference indicated that between $78-90 \%$ of the $\mathrm{Hg}$ emitted from the source was present as GOM rather than GEM, similar to the literature values tabulated in Table 2 and Table 3. 


\subsection{Future work}

\subsubsection{Determining the Reproducibility of Replicate GOM Source Vials}

As described in section 3.6.4 a duplicate source was used during this work to replace the original source vial that had become contaminated, and it was verified that both emitted similar quantities of $\mathrm{Hg}$. However, it would be desirable to determine the uncertainty level within the system between duplicate sources, and sources that are similarly, but not identically constructed. The following procedure might be used:

1. Obtain 3 identical capillary-necked vials to be used as the GOM source vial. Each of these should be cleaned using stannous chloride solution, rinsed, dried then filled with the same amount $\left(2-3\right.$ grams) of $\mathrm{HgCl}_{2}$.

2. Determine the emission rate of each source at consistent sampling conditions using a similar procedure to that used in section 3.6.4.

3. After determining the emission rate of each vial, the $\mathrm{HgCl}_{2}$ in each vial is disposed of, and the vial cleaned. Following this, the vials are refilled with $\mathrm{HgCl}_{2}$, one with the same quantity of $\mathrm{HgCl}_{2}$ as previously, one with $20-$ $25 \%$ more $\mathrm{HgCl}_{2}$, and the last with $20-25 \%$ less $\mathrm{HgCl}_{2}$.

4. Each vial is then retested using the same procedure as before.

It would be of interest to know not only whether 3 identically constructed GOM source vials perform identically, but also whether a vial, if emptied and refilled, continues to emit the same quantity of GOM, and whether the exact quantity of GOM in each vial matters, or whether only the surface area present is important. 


\subsubsection{Extended Testing of Increased Source Flow Rates}

It was observed, as described in section 3.4, that flow rates in excess of 1 L/min are potentially effective at decreasing the concentration of GOM. However, when used with the experimental conditions of $-15^{\circ} \mathrm{C}$, increased flow rates were ineffective at decreasing the source concentration due to the difficulty in cooling $20^{\circ} \mathrm{C}$ air to $-15^{\circ} \mathrm{C}$ at a flow rate of up to $5 \mathrm{~L} / \mathrm{min}$. The originally used cooling system was a $5 \mathrm{~m}$ length of 1/8" copper tubing, the longer $10 \mathrm{~m}$ length of $1 / 8$ " copper tubing was found to be more effective at cooling the system, but it was insufficient to control the source temperature at $5 \mathrm{~L} / \mathrm{min}$. Repeating this procedure from section 3.6.3 using a variety of lengths of copper tubing $(15,20,30 \mathrm{~m}$, etc) would be useful to determine whether it is potentially possible to maintain the source temperature at higher flow rates. However, the compressed air source that was used during this work was insufficiently pressurized ( $\sim 50 \mathrm{PSIG})$ to maintain more than $\sim 9$ $\mathrm{L} / \mathrm{min}$ flow rate when a $5 \mathrm{~m}$ copper coil was used, and no more than approximately $6 \mathrm{~L} / \mathrm{min}$ when a $10 \mathrm{~m}$ copper coil was used. Consequently, an air source will be needed that can provide higher pressure to the system if increased lengths of tubing are to be tested. 


\subsection{References}

1. Schroeder, W. H. \& Munthe, J. Atmospheric mercury - An overview. Atmos. Environ. 32, 809-822 (1998).

2. Beckers, F. \& Rinklebe, J. Cycling of mercury in the environment: Sources, fate, and human health implications: A review. Crit. Rev. Environ. Sci. Technol. 47, 693-794 (2017).

3. Clever, H. L., Johnson, S. A. \& Derrick, M. E. The solubility of some sparingly soluble mercury salts in water and aqueous electrolyte solutions. Journal of Physical and Chemical Reference Data 14, 631-680 (1985).

4. UNEP. Global Mercury Assessment 2013: Sources, Emissions, Releases, and Environmental Transport. Unep (2013).

5. Landis, M. S., Stevens, R. K., Schaedlich, F. \& Prestbo, E. M. Development and characterization of an annular denuder methodology for the measurement of divalent inorganic reactive gaseous mercury in ambient air. Environ. Sci. Technol. 36, 3000-3009 (2002).

6. Munthe, J. et al. Intercomparison of methods for sampling and analysis of atmospheric mercury species. Atmos. Environ. 35, 3007-3017 (2001).

7. Lindberg, S. E. et al. FORMATION OF REACTIVE GASEOUS MERCURY IN THE ARCTIC : 295-302 (2001).

8. Kos, G. et al. Evaluation of discrepancy between measured and modelled oxidized mercury species. Atmos. Chem. Phys. 13, 4839-4863 (2013).

9. Lindberg, S. E. \& Stratton, W. J. Atmospheric Mercury Speciation : Concentrations and Behavior of Reactive Gaseous Mercury in Ambient Air. Environ. Sci. Technol. 32, 49-57 (1998).

10. Zhang, L. et al. Mercury transformation and speciation in flue gases from anthropogenic emission sources: A critical review. Atmos. Chem. Phys. 16, 24172433 (2016).

11. Sonke, J. E., Heimbürger, L. E. \& Dommergue, A. Mercury biogeochemistry: Paradigm shifts, outstanding issues and research needs. Comptes Rendus Geosci. 345, 213-224 (2013).

12. Honda, S., Hylander, L. \& Sakamoto, M. Recent advances in evaluation of health effects on mercury with special reference to methylmercury-A minireview. Environ. Health Prev. Med. 11, 171-176 (2006).

13. Pereiro, I. R., Wasik, A. \& Łobiński, R. Determination of mercury species in fish reference materials by isothermal multicapillary gas chromatography with atomic emission detection after microwave-assisted solubilization and solvent extraction. J. Anal. At. Spectrom. 13, 743-747 (1998).

14. Hadeishi, A. T., Church, D. A., Mclaughlin, R. D., Zak, B. D. \& Nakamura, M. Mercury Monitor for Ambient Air Published by: American Association for the 
Advancement of Science Stable URL : http://www.jstor.org/stable/1739378. 187, 348-349 (1975).

15. EPA, U. EPA Method 29 Determination of Metals Emissions from Stationary Sources. (2014).

16. Laudal, D., Heidt, M., Galbreath, K., Nott, B. \& Brown, T. State of the Art: Mercury Speciation Measurement in Coal Combustion Systems. in Proceedings of the Air \& Waste Management Exhibition 301, (1997).

17. Stratton, W. J., Lindberg, S. E. \& Perry, C. J. Atmospheric mercury speciation: Laboratory and field evaluation of a mist chamber method for measuring reactive gaseous mercury. Environ. Sci. Technol. 35, 170-177 (2001).

18. Xiao, Z., Sommar, J., Wei, S. \& Lindqvist, O. Sampling and determination of gas phase divalent mercury in the air using a $\mathrm{KCl}$ coated denuder. Fresenius. J. Anal. Chem. 358, 386-391 (1997).

19. Possanzini, M., Febo, A. \& Liberti, A. New design of a high-performance denuder for the sampling of atmospheric pollutants. Atmos. Environ. 17, 2605-2610 (1983).

20. Huang, J. \& Gustin, M. S. Uncertainties of gaseous oxidized mercury measurements using KCL-coated denuders, cation-exchange membranes, and nylon membranes: Humidity influences. Environ. Sci. Technol. 49, 6102-6108 (2015).

21. Jaffe, D. A. et al. Progress on understanding atmospheric mercury hampered by uncertain measurements. Environ. Sci. Technol. 48, 7204-7206 (2014).

22. Lyman, S. et al. Automated Calibration of Atmospheric Oxidized Mercury Measurements. Environ. Sci. Technol. 50, 12921-12927 (2016).

23. Huang, J., Miller, M. B., Weiss-Penzias, P. \& Gustin, M. S. Comparison of gaseous oxidized $\mathrm{Hg}$ measured by $\mathrm{KCl}$-coated denuders, and nylon and cation exchange membranes. Environ. Sci. Technol. 47, 7307-7316 (2013).

24. Lyman, S. N., Jaffe, D. A. \& Gustin, M. S. Release of mercury halides from KCl denuders in the presence of ozone. Atmos. Chem. Phys. 10, 8197-8204 (2010).

25. Gustin, M. S. et al. Do we understand what the mercury speciation instruments are actually measuring? Results of RAMIX. Environ. Sci. Technol. 47, 7295-7306 (2013).

26. Swartzendruber, P. C., Jaffe, D. A. \& Finley, B. Development and first results of an aircraft-based, high time resolution technique for gaseous elemental and reactive (oxidized) gaseous mercury. Environ. Sci. Technol. 43, 7484-7489 (2009).

27. Larjava, K., Laitinen, T., Kiviranta, T., Siemens, V. \& Klockow, D. Application of the diffusion screen technique to the determination of gaseous mercury and mercury (II) chloride in flue gases. Int. J. Environ. Anal. Chem. 52, 65-73 (1993).

28. Wang, J., Xiao, Z. \& Lindqvist, O. On-line measurement of mercury in simulated flue gas. Water, Air, Soil Pollut. 80, 1217-1226 (1995). 
29. Feng, X., Lu, J. Y., Hao, Y., Banic, C. \& Schroeder, W. H. Evaluation and applications of a gaseous mercuric chloride source. Anal. Bioanal. Chem. 376, 1137-1140 (2003).

30. Feng, X. B. et al. Modified on-line monitoring of total gaseous mercury in flue gases using Semtech (R) Hg 2000 analyzer. Fresenius J. Anal. Chem. 368, 528$533(2000)$.

31. O'Keeffe, A. E. \& Ortman, G. C. Primary Standards for Trace Gas Analysis. Anal. Chem. 38, 760-763 (1966).

32. McClure, C. D., Jaffe, D. A. \& Edgerton, E. S. Evaluation of the $\mathrm{KCl}$ denuder method for gaseous oxidized mercury using $\mathrm{HgBr} 2$ at an in-service AMNet site. Environ. Sci. Technol. 48, 11437-11444 (2014). 